\title{
Synthesis and Characterization of Chitosan/Agar/SiO2 Nano Hydrogels For Removal of Amoxicillin and of Naproxen From Pharmaceutical Contaminants
}

Omid Moradi ( $\nabla$ moradi.omid@gmail.com )

IAU: Islamic Azad University https://orcid.org/0000-0002-3283-6254

Samira Mhdavi

IAU: Islamic Azad University

Sajjad Sedaghat

IAU: Islamic Azad University

\section{Research Article}

Keywords: Hydrogels, nanocomposite, naproxen, amoxicillin, pharmaceutical contaminants

Posted Date: February 15th, 2021

DOl: https://doi.org/10.21203/rs.3.rs-189441/v1

License: (c) (1) This work is licensed under a Creative Commons Attribution 4.0 International License.

Read Full License 


\section{Abstract}

Today, environmental pollutants pose a threat to human societies and all living organisms, which is why they have attracted the attention of environmental researchers. In this study, in order to remove pharmaceutical contaminants Naproxen and Amoxicillin from aqueous media with $\mathrm{SiO}_{2}$ nanoparticles based on Agar and Chitosan was investigated. The study of structural properties, physical and chemical characterization of synthesized nanocomposite was investigated by FTIR, XRD, TEM, FE-SEM, DLS and EDX analyzes. In addition, the role of parameters affecting the removal of pharmaceutical contaminants such as solution $\mathrm{pH}$, contact time, contaminant concentration and temperature were studied.

Nanocomposites prepared from Agar and Chitosan showed good performance in absorbing naproxen and amoxicillin. According to the studies performed to remove naproxen, the max adsorption efficiency was obtained at a concentration of $20 \mathrm{mg} / \mathrm{l}$ with an absorbent dose of $0.05 \mathrm{~g}$ and a pH of 8 and at an optimum temperature of $25{ }^{\circ} \mathrm{C}$ and $99 \%$ in $15 \mathrm{~min}$. Also, for amoxicillin with nanocomposite prepared with an initial concentration of $20 \mathrm{mg} / \mathrm{l}$ and an adsorbent dose of $0.05 \mathrm{~g}$, a time of $10 \mathrm{~min}$, a temperature of $25^{\circ} \mathrm{C}$ and a pH of 8 , the max removal efficiency of $91.15 \%$ was obtained.

\section{Introduction}

Pharmaceutical and personal care products are emerging pollutants in water resources that the presence of these products, even in very small quantities, can have adverse effects on the environment. Due to the growing population, according to the forecasts by 2050 , the demand for water, food and energy will increase significantly by $50 \%, 70 \%$ and $80 \%$, respectively[1]. Today, contaminated of the natural water environment by pharmaceutical compounds and personal care products is widespread, and the substances used to treat and prevent disease in humans and animals are compounds in non-steroidal groups [2]. According to research conducted in recent years, the presence of sustainable organic compounds such as pharmaceutical and personal care products in effluents and drinking water sources is about $\mu$-ng/l. pharmaceutical compounds and their derivatives due to biological activity and stability in the environment can cause carcinogenesis and mutagenicity in humans, so it must be purified before discharge to the environment. Therefore, the elimination of antibiotics, anti-cancer pharmaceutical, cardiovascular, growth stimulants and anti-parasites are of great importance.[3]. Also, according to the reports of the US Food and Pharmaceutical Administration (FDA), the concentration of ingredients in pharmaceutical released into the environment is about $0.1 \mu \mathrm{g} / \mathrm{I}[4]$. Naproxen is a non-steroidal antiinflammatory pharmaceutical that does not contain corticosteroids, which block the production of prostaglandins, which are responsible for causing pain and inflammation in the affected area[5,6]. Amoxicillin, a component of the antibiotic $\beta$-lactam, binds to the penicillin-binding protein (PBP) to inhibit trans peptidases and inhibit the production of bacterial cell wall peptidoglycans, thereby destroying the bacterial cell wall. Among the uses of these pharmaceutical s are pain relief in the treatment of many infections, such as arthritis, muscle spasms, sinusitis, urinary tract infections, and so on[7,8]. The chemical structure of naproxen and amoxicillin is shown in Figure 1. 
Recently, extensive research has been conducted on the removal of pharmaceutical contaminants, using photocatalytic and adsorbent materials that are biophilic and without any secondary contamination[912]. Adsorption processes can be performed through interactions between molecules of contaminants and adsorbents and mainly include hydrogen bonding, electrostatic bonding interactions and $\pi-\pi$ interactions[13-17]. The adsorption process is also one of the most common and effective wastewater treatment processes that has been considered by many researchers due to its high efficiency, ease of operation and cost-effectiveness[18]. $\mathrm{SiO}_{2}$ particles are spherical shapes and are of special importance due to their unique properties such as high active surface area, high mechanical and thermal resistance, non-toxicity, high porosity, dispersibility in different solvents and environmental compatibility. It has the ability to be an adsorbent or catalyst base, sensors and pharmaceutical carriers[19-22]. Agar extracted from agrophytic algae has a linear polymer structure in nature that is a combination of agarose polysaccharide and agaropectin and is chemically galactane sulfuric ester. Polymer agar can be a potential material as a compound of adsorbent due to its thermal and biodegradability and water resistance, biodegradability, availability and cost-effectiveness[23-26].Chitosan is a natural polymer derived from cationic polysaccharides, non-toxic and degradable. It also has $\mathrm{OH}$ and $\mathrm{NH}_{2}$ functional groups, which can show a significant interaction effect for organic molecules in pharmaceutical uptake. Chitosan has been used in various fields as a biomaterial in antimicrobial resistance, tissue repair, cell adhesion and pharmaceutical delivery systems[27-31].

So far, various methods have been used to remove pharmaceutical contaminants from wastewater, including membrane processes, chemical oxidation, ionic and biological treatment, photofenton decomposition and adsorption, as well as adsorbents such as activated carbon, ash and zeolite[6,32,33]. Therefore, the synthesis of adsorbents based on nanoparticles with high surface area, high porosity and adsorption capacity, as well as the ability to separate quickly and easily is essential. One of these methods is the use of natural polymers and $\mathrm{SiO}_{2}$ nanoparticles that have high porosity and surface area[34-39]. The inability of contamination treatment plants to remove highly polar micro-contaminated and antibiotics that have entered surface and groundwater sources exacerbates many concerns about microbial and pharmaceutical resistance. Therefore, researchers seek to optimize the adsorption process and achieve new adsorbents with lower cost and higher adsorption capacity[40].

Nodeh and et al. of a GO-MNPs-SiO ${ }_{2}$ nanocomposite as an adsorbent for the removal of naproxen. Doping of magnetic $\mathrm{Fe}_{3} \mathrm{O}_{4}$ nanoparticles to $\mathrm{GO}$ improves permeability and prevents clotting and rapid recovery. The results showed that naproxen was removed by van der Waals interaction force, electrostatic repulsion force and hydrogen bonding. The adsorption capacity with the above adsorbent at $\mathrm{pH}=5$ was equal to $31 \mathrm{mg} / \mathrm{g}$ and also the maximum removal percentage was 90\%[5]. Conducted and et al. a study to remove ibuprofen, diclofenac, and naproxen from water using chitosan-modified rubber tire residues. The results showed that the larger size range of the modified rubber waste tire depends on the chitosan density. As the absorbent dose increases, the absorption rate increases from $25 \%$ to $96 \%$. In acidic conditions, due to the protonation of the amine groups in chitosan with a positive charge of the carboxylic group in anti-inflammatory pharmaceutical s, the absorption process has been unfavorable. 
Also, due to the balance of electrostatic force between chitosan and pharmaceutical in the $\mathrm{pH}$ range of 36, diclofenac, ibuprofen and ibuprofen were more absorbed, respectively[2]. Rahmani Sani et al. Conducted a study using carbon nanotubes to remove the antibiotic sulfadimethoxine from aqueous solutions, which are dangerous environmental pollutants. The results showed that the maximum removal efficiency at $\mathrm{pH}=6$ with an adsorbent dose of $0.04 \mathrm{~g}$ with an initial concentration of $20 \mathrm{mg} / \mathrm{g}$, which was $94.5 \%$. Studies show that the Langmuir model is more consistent with the data obtained[40]. Rakhshaei et al. performed a study using synthesized CS-GeL/nZnO nanocomposite scaffolds to heal wounds and increase the antibacterial effects of naproxen. These scaffolds act as a temporary matrix for the proliferation and growth of damaged tissue cells. The bioactivity of chitosan alone is poor and therefore biologically active substances such as collagen or gelatin have been used to overcome these conditions. The micrographs prepared from the scaffolds have well-connected pores with a pore size in the range of 400-50 $\mathrm{nm}$, and therefore the proper hydrogen bond interaction between CS-GeL/nZnO indicates that a size of about $40 \mathrm{~nm}$ is suitable for cell growth[41]. Ning et al. With the synthesis of $\mathrm{CS} / \mathrm{SiO}_{2} / \mathrm{CNTs}$ nanocomposites to investigate the adsorption properties of Direct Blue and Reactive Blue dyes from aqueous solution. The results showed that the maximum adsorption rate occurred at $\mathrm{pH}=6$ for direct blue dye and at $\mathrm{pH}=2$ for reactive blue dye, and also the Langmuir isotherm is consistent with the experimental data[42]. In a study Noori et al. of LDH/Al-Mg was investigated to remove carbamazepine, cephalexin, ciproflucan from aqueous media. The results showed that the highest elimination of antibiotics at the time of contact for 120 minutes, the dose of adsorbent per gram of 8 liters and the initial concentration of $30 \mathrm{mg} / \mathrm{l}$ for carbamazepine, cephalexin, ciprofloxacin were $94 \%, 91 \%$ and $97 \%$, respectively. Also, isotherm and kinetics studies showed that the adsorption data are consistent with the Freundlich and quasi-quadratic model[43].

In this study, in order to remove pharmaceutical contaminants from aqueous media with $\mathrm{SiO}_{2}$ nanoparticles based on Agar and Chitosan was investigated. The study of structural properties, physical and chemical characterization of synthesized nanocomposites was investigated by FTIR, XRD, TEM, FESEM, DLS and EDX analyzes. In addition, the role of parameters affecting the removal of pharmaceutical contaminants such as solution $\mathrm{pH}$, contact time, contaminant concentration and temperature were studied. Nanocomposites prepared from Agar and Chitosan showed good performance in absorbing naproxen and amoxicillin. Nanocomposites prepared as adsorbents were used to remove naproxen and amoxicillin by physical adsorption from aqueous media to take steps to improve the removal of pharmaceutical contaminants from the environment and water and industrial effluents.

\section{Experimental}

\subsection{Materials}

Silicon oxide $\left(\mathrm{SiO}_{2}\right)$ nanoparticle powder was purchased from US Research Nanomaterials. Agar powder was purchased from Merck, as well as chitosan powder, pharmaceutical amoxicillin and naproxen from 
Sigma Aldrich. Deionized water was prepared from Neutron Company, cellulose microfilter and 0.22 micrometer syringe filter from Membrane Filter Company.

\subsection{Synthesis of Nanocomposites}

\subsubsection{Synthesis of chitosan/ $/ \mathrm{Si}_{2}$ nanocomposites}

First, $1 \mathrm{~g}$ of chitosan powder was added to $100 \mathrm{ml}$ of $0.1 \mathrm{M}$ acetic acid and placed on a heater-magnet for $60 \mathrm{~min}$ at $60^{\circ} \mathrm{C}$ to obtain a completely uniform solution. On the other hand, $0.05 \mathrm{~g}$ of nanoparticles of $\mathrm{SiO}_{2}$ was added in $100 \mathrm{ml}$ of deionized water and mixed for $60 \mathrm{~min}$ at $50^{\circ} \mathrm{C}$ until the solution was completely uniform. The two solutions containing chitosan and $\mathrm{SiO}_{2}$ were then mixed together and placed in an ultrasonic device for $30 \mathrm{~min}$ at $40^{\circ} \mathrm{C}$ until completely dispersed. He was then refluxed/ultrasonic for $24 \mathrm{~h}$ at a rate of $60 \mathrm{~min} / 15 \mathrm{~min}$. Finally, the resulting mixture was passed through a $0.22 \mu \mathrm{m}$ cellulose microfilter using a Buchner funnel and an air pump and dried in an oven at $60^{\circ} \mathrm{C}$ for $12 \mathrm{~h}$.

\subsubsection{Synthesis of Agar/chitosan/ $\mathrm{SiO}_{2}$ nanocomposites}

First, $1.05 \mathrm{~g}$ of agar powder/ $\mathrm{SiO}_{2}$ was added to $100 \mathrm{ml}$ of deionized water and placed on a heatermagnet for $1 \mathrm{~h}$ at $60^{\circ} \mathrm{C}$ to form a uniform solution. On the other hand, add $1.05 \mathrm{~g}$ of agar powder to 100 $\mathrm{ml}$ of deionized water and mix for $1 \mathrm{~h}$ at $60^{\circ} \mathrm{C}$ to form a uniform solution. The above solutions were then mixed together and placed in an ultrasonic device for $40 \mathrm{~min}$ at $40^{\circ} \mathrm{C}$ to disperse. He was then refluxed/ultrasonic for 24 hours at a rate of $60 \mathrm{~min} / 15 \mathrm{~min}$. Finally, the resulting precipitate was centrifuged and passed through a $0.22 \mu \mathrm{m}$ cellulose microfilter using a Buchner funnel and an air pump. The material was dried in an oven at $60^{\circ} \mathrm{C}$ for $12 \mathrm{~h}$.

\subsection{Apparatus}

\subsection{Pharmaceutical Adsorption Experiment}

Naproxen and amoxicillin at a concentration of $40 \mathrm{mg} / \mathrm{l}$ were investigated using synthesized nanocomposite adsorbents. The maximum absorption peak appeared for naproxen $330 \mathrm{~nm}$ and amoxicillin $272 \mathrm{~nm}$. The amount of $0.04 \mathrm{~g}$ of the mentioned pharmaceutical was selected and reached a volume of $1000 \mathrm{I}$. Then a certain volume of the above solution was selected and brought to different concentrations. The concentration of the remaining molecules in the solution was isolated by a $0.22 \mu \mathrm{m}$ syringe microfilter and measured using a UV-Visible spectrophotometer. In this study, the effect of different factors on the adsorption process such as $(\mathrm{pH}=8)$, adsorbent dose of $0.05 \mathrm{~g}$, contact time (5$240 \mathrm{~min}$ ) and different temperatures were investigated. The removal efficiency, adsorption capacity qt 
$(\mathrm{mg} / \mathrm{g})$ at time $\mathrm{t}(\mathrm{min})$ and the adsorption capacity at equilibrium qe $(\mathrm{mg} / \mathrm{g})$ were calculated from the following equations:

$R \%=\frac{\left(C_{0}-C_{t}\right)}{C_{0}} * 100$

$q_{\mathrm{t}}=\frac{\left(C_{0}-C_{t}\right) V}{m}$

$q_{e}=\frac{\left(C_{0}-C_{e}\right) V}{m}$

\section{Results And Discussion \\ 3.1. Characterization}

\subsubsection{FTIR}

FTIR spectrum was used to characterization the functional groups of synthesized nanocomposite materials. The results of FTIR for the synthesized samples are given in Fig.2. According to Fig.2.a, the peaks appearing for chitosan nanoparticles at positions $3434 \mathrm{~cm}^{-1}, 1604 \mathrm{~cm}^{-1}$ and $1074 \mathrm{~cm}^{-1}$ correspond to the tensile vibrations of $\mathrm{OH}, \mathrm{C}=\mathrm{C}$ and $\mathrm{C}-\mathrm{O}$ alkoxy, respectively[44]. For $\mathrm{SiO}_{2}$ nanoparticles, the peaks appearing in positions $3432 \mathrm{~cm}^{-1}, 1381 \mathrm{~cm}^{-1}$ and $1074 \mathrm{~cm}^{-1}$ are related to the tensile vibrations of $\mathrm{OH}, \mathrm{C}=$ $\mathrm{C}$ and $\mathrm{C}-\mathrm{O}$ alkoxy and the peak $572 \mathrm{~cm}^{-1}$ belongs to the $\mathrm{SiO}_{2}$ group (Fig.2.b)[45]. Also, the peaks observed in $3532 \mathrm{~cm}^{-1}, 2898 \mathrm{~cm}^{-1}$ and $1658 \mathrm{~cm}^{-1}$ are related to $\mathrm{OH}, \mathrm{C}=\mathrm{H}$ and $\mathrm{C}=\mathrm{C}$ tensile strength in agar, respectively (Fig.2.c)[46]. Peaks observed for Agar/Chitosan samples at positions $3740 \mathrm{~cm}^{-1}$ (correspond to the group $\mathrm{N}-\mathrm{H}$ ), $3444 \mathrm{~cm}^{-1}$ (correspond to the group $\mathrm{O}-\mathrm{H}$ ), $1617 \mathrm{~cm}^{-1}$ (correspond to the group $\mathrm{C}=\mathrm{O}$ ), $1058-1368 \mathrm{~cm}^{-1}$ (correspond to the group $\mathrm{C}-0$ ) and 572 it is related to the presence of $\mathrm{Si}=0$ group on the nanocomposite (Fig.2.d). Observed peaks of Chitosan/ $\mathrm{SiO}_{2}$ nanocomposites in positions 3737 (correspond to the group $\mathrm{N}-\mathrm{H}$ ), $3413 \mathrm{~cm}^{-1}$ (correspond to the group $\mathrm{O}-\mathrm{H}$ ), $16413740 \mathrm{~cm}^{-1}$ ( $\mathrm{C}=\mathrm{C}$ correspond to the group), $1068 \mathrm{~cm}^{-1}$ (C-0 correspond to the group) and $687 \mathrm{~cm}^{-1}$ and $646 \mathrm{~cm}^{-1}$ correspond to the belong to the $\mathrm{C}-\mathrm{C}$ group (Fig.2.e). For Agar/Chitosan/ $\mathrm{SiO}_{2}$ nanocomposites, the peaks observed in 3435, $1640 \mathrm{~cm}^{-1}$ and $537 \mathrm{~cm}^{-1}$ belong to the tensile group $\mathrm{OH}, \mathrm{C}=\mathrm{C}$ and $\mathrm{Si}=\mathrm{O}$, respectively.

\subsubsection{XRD}

The crystal structures of Agar/Chitosan, Chitosan/ $/ \mathrm{SiO}_{2}$ and $\mathrm{Agar} / \mathrm{Chitosan} / \mathrm{SiO}_{2}$ nanocomposites were investigated by X-ray diffraction (XRD). The results showed that they were consistent with previous

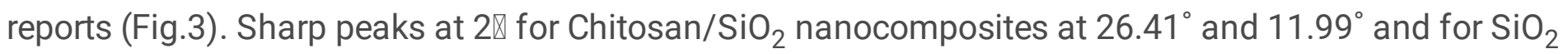


nanoparticles at $42.29^{\circ}$, representing amorphous carbon in the structure (Fig .3.C). As shown in Fig. 3.d,

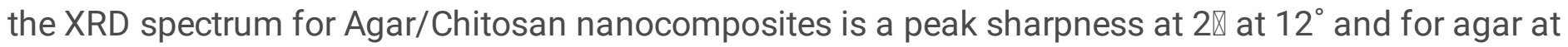
$28^{\circ}$ and $42^{\circ}$ representing amorphous carbon. According to Fig .3. e for Agar/Chitosan/SiO ${ }_{2}$

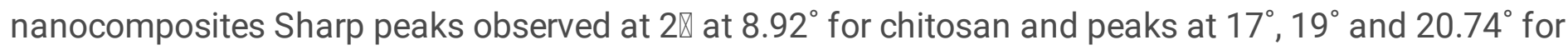
$\mathrm{SiO}_{2}$ as well as peaks at $26.47^{\circ}$ And $42.52^{\circ}$ indicates amorphous carbon in the structure[47-49].

\subsubsection{TEM and FE-SEM}

FE-SEM image was taken from synthesized Agar/Chitosan, Chitosan $/ \mathrm{SiO}_{2}$ and Chitosan/Agar/SiO 2 nanocomposites to investigate morphology and particle size (Fig.4). According to the FE-SEM image of Fig.4.a for Agar/Chitosan nanocomposites, the particle size varies from 22.33 - $35.73 \mathrm{~nm}$. According to the fig.4.b The morphology of $\mathrm{SiO}_{2}$ nanoparticles and its presence in the final product is clearly confirmed and for Chitosan $/ \mathrm{SiO}_{2}$ nanocomposites the size of nanoparticles is between $24.56-42.43 \mathrm{~nm}$. The image of Chitosan/Agar/ $/ \mathrm{SiO}_{2}$ nanoparticle nanocomposite is shown in Fig.4.c which shows the morphology of $\mathrm{SiO}_{2}$ nanoparticles and its presence in the final product. According to the image TEM fig. 5 the morphology of $\mathrm{SiO}_{2}$ nanocomposites is hexagonal and the particle size varies from 30 to $300 \mathrm{~nm}$.

\subsubsection{EDX}

EDX analysis was performed to evaluate elemental analysis of synthesized nanocomposite materials (Fig.6). According to Fig.6.a for Agar/Chitosan nanocomposites, there is about $51.6 \%$ by weight of carbon atoms, $28.9 \%$ by weight of oxygen and $19.4 \%$ by weight of nitrogen in the synthesized nanocomposite structure. According to the results of EDX analysis, about $52 \%$ by weight of carbon atom, $24.2 \%$ by weight of oxygen, $16.5 \%$ by weight of nitrogen and $7.2 \%$ of silicon oxide are present in the Chitosan $/ \mathrm{SiO}_{2}$ nanocomposite, which clearly confirms the presence of silicon oxide (Fig.6.b). For Agar/Chitosan/SiO 2 oxide nanocomposites, there is about $46.3 \%$ by weight of carbon atom, $35.3 \%$ by weight of oxygen, $12.7 \%$ by weight of nitrogen and $5.9 \%$ by weight of silicon oxide in the sample structure (Fig.6.c).

\subsubsection{DLS (Dynamic light scattering)}

The light scattering spectrum of Agar/Chitosan $/ \mathrm{SiO}_{2}$ nanocomposites is shown in Fig.7. As it is known, the synthesized sample was in the size of $100 \mathrm{~nm}$ and less and its maximum amount was in the range of $100 \mathrm{~nm}$ based on its number.

\subsection{Pollutant removal}

\subsubsection{Initial concentration pollutant}


Effect of initial concentration on naproxen and amoxicillin pharmaceutical with synthesized adsorbents in different concentrations $(10,30,20$ and $40 \mathrm{mg} / \mathrm{l})$ in $25 \mathrm{ml}$ of pharmaceutical solution with optimal adsorbent amount $(0.05 \mathrm{~g})$ and with optimal pH adjustment (8) was investigated at specified intervals (40 $\mathrm{min})$ on a magnetic stirrer at room temperature $\left(25^{\circ} \mathrm{C}\right)$. According to Fig.8. $(\mathrm{a}, \mathrm{b})$, the maximum amount of adsorption for naproxen with Agar/Chitosan and Agar/Chitosan/ $\mathrm{SiO}_{2}$ nanocomposite adsorbents occurred at a concentration of $10 \mathrm{mg} / \mathrm{l}$, which is equal to $99 \%$, which with increasing initial concentration to $40 \mathrm{mg} / \mathrm{l}$, the removal efficiency reached its maximum value and its value remains constant and more active adsorption sites are used and filled, so that after a certain concentration the removal efficiency does not change and remains constant. The maximum adsorption for amoxicillin with Agar/Chitosan and Agar/Chitosan/ $\mathrm{SiO}_{2}$ nanocomposite adsorbents occurred at initial concentrations of $20 \mathrm{mg} / \mathrm{l}$, with removal efficiencies of $97.85 \%$ and $87.9 \%$, respectively, and with increasing concentration to $40 \mathrm{mg} / \mathrm{l}$ more than The active adsorption sites are used and filled so that the removal efficiency is independent of the concentration and its value remains constant (Fig.8. (c, d))[50-54].

\subsubsection{Effect $\mathrm{pH}$}

The $\mathrm{pH}$ of the solution is one of the most important factors in the adsorption process that can change the surface charge of adsorbents as well as the separation of functional groups in the active sites of adsorbent adsorption. Therefore, it is very important and necessary to study the effect of $\mathrm{pH}$ on the removal process. Effect of solution $\mathrm{pH}$ on naproxen and amoxicillin with Agar/Chitosan and Agar/Chitosan/ $\mathrm{SiO}_{2}$ at different $\mathrm{pHs}$ in $25 \mathrm{ml}$ of pharmaceutical solution with optimal concentration (20 $\mathrm{mg} / \mathrm{l})$, optimal adsorbent $(0.05 \mathrm{~g})$ and was tested for $40 \mathrm{~min}$ on a stirrer at room temperature $\left(25^{\circ} \mathrm{C}\right)$. The results of this study are shown in Fig.9. As shown in Fig.9. (a, b), the removal efficiency of naproxen with Agar/Chitosan and Agar/Chitosan/ $\mathrm{SiO}_{2}$ adsorbents did not increase significantly with increasing the $\mathrm{pH}$ of the solution from 6 to 10 , and the removal efficiency at $\mathrm{pH}=6$ was at its $\max 99 \%$. It can be said that slight competition between pharmaceutical ions increases the $\mathrm{pH}$ due to decreasing the concentration of $\mathrm{H}^{+}$ions to bind to the adsorbent surface causing a slight change, so $\mathrm{pH}=6$ was considered effective. The removal efficiency of amoxicillin with Agar/Chitosan and Agar/Chitosan/ $\mathrm{SiO}_{2}$ adsorbents reaches its max value of $68 \%$ and $84 \%$ by increasing the $\mathrm{pH}$ of the solution from 4.6 to 8.6 , respectively, at $\mathrm{pH} 7.6$, 8.6. From Fig.9. (c, d) * it can be seen that by increasing the $\mathrm{pH}$ of the solution, the removal efficiency increases and increasing the $\mathrm{pH}$ of the solution increases the number of hydroxyl groups, which increases the number of active sites with a negative charge between the pharmaceutical and the adsorbent surface[55,56].

\subsubsection{Adsorption contact time}

Effect of contact time on absorption of naproxen and amoxicillin with synthesized Agar/chitosan and Agar/chitosan $/ \mathrm{SiO}_{2}$ adsorbents in the time range of 5-240 min and by keeping other parameters constant (initial concentration $20 \mathrm{mg} / \mathrm{l}$, the amount of adsorbent was $0.05 \mathrm{~g}$ and $\mathrm{pH}=8$ ) at room temperature. The 
results of this study are shown in Fig.10. As shown in Fig.10 (a-d), the uptake of these pharmaceutical with Agar/chitosan and Agar/chitosan/ $\mathrm{SiO}_{2}$ adsorbents did not change much over time and reached equilibrium in the early times. Rapid pharmaceutical uptake in the early stages of the uptake process can be attributed to multiple voids and active sites of the adsorbent surface[57,58]. The results showed that the optimal values of contact time for removal of naproxen and amoxicillin with Agar/chitosan and Agar/chitosan $/ \mathrm{SiO}_{2}$ adsorbents were $99 \%, 90 \%, 80 \%$ and $90 \%$ in the first $10 \mathrm{~min}$, respectively.

\subsubsection{Impact temperature}

The effect of temperature on the adsorption of naproxen and amoxicillin with nanocomposite adsorbents of Agar/chitosan and Agar/chitosan/ $\mathrm{SiO}_{2}$ at specified intervals ( $5-30 \mathrm{~min}$ ) and by keeping other parameters constant (initial concentration $20 \mathrm{mg} / \mathrm{l}$, the amount of adsorbent $(0.05 \mathrm{~g}$ and pH $=8$ ) was evaluated at different temperatures $\left(10,15,20,25\right.$ and $\left.30^{\circ} \mathrm{C}\right)$. The results of this study are presented in Fig.11. According to Fig.11. (a, b), with increasing temperature from 10 to $30^{\circ} \mathrm{C}$, the removal efficiency for naproxen for both adsorbents is $99 \%$ and is temperature independent. Also, for amoxicillin with increasing temperature from 10 to $30^{\circ} \mathrm{C}$, the removal efficiency for Agar/chitosan adsorbent at $20^{\circ} \mathrm{C}$ is $67.35 \%$ and for Agar/chitosan/ $\mathrm{SiO}_{2}$ adsorbent at $30^{\circ} \mathrm{C}$ is $87.75 \%$. Because the velocity of pharmaceutical molecules is controlled by temperature, the rate of removal does not change with temperature. In other words, with increasing temperature due to greater resistance of viscous forces, reduces the molecules of the pharmaceutical in the outer boundary layer and the inner pores of the adsorbent particles. On the other hand, the small size of the particle pores causes more resistance to particle emission[59,60].

\section{Conclusion}

In this study, in order to removal of pharmaceutical contaminants from aqueous media with nanocomposite Agar/Chitosan/ $\mathrm{SiO}_{2}$ was investigated. The study of structural properties, physical and chemical characterization of synthesized nanocomposites was investigated by FTIR, XRD, TEM, FE-SEM, DLS and EDX analyzes. Nanocomposites prepared from Agar and Chitosan showed good performance in absorbing naproxen and amoxicillin. According to the studies performed to remove naproxen, the max adsorption efficiency was obtained at a concentration of $20 \mathrm{mg} / \mathrm{l}$ with an absorbent dose of $0.05 \mathrm{~g}$ and a $\mathrm{pH}$ of 8 and at an optimum temperature of $25^{\circ} \mathrm{C}$ and $99 \%$ in $15 \mathrm{~min}$. Also, for amoxicillin with nanocomposite prepared with an initial concentration of $20 \mathrm{mg} / \mathrm{l}$ and an adsorbent dose of $0.05 \mathrm{~g}$, a time of 10 min, a temperature of $25^{\circ} \mathrm{C}$ and a pH of 8 , the max removal efficiency of $91.15 \%$ was obtained.

\section{References}

1. Márquez G, Rodríguez EM, Beltrán FJ, Álvarez PM (2014) Solar photocatalytic ozonation of a mixture of pharmaceutical compounds in water. Chemosphere 113:71-78.

https://doi.org/10.1016/j.chemosphere.2014.03.093 
2. B. Warintorn Phasuphan a, Narong Praphairaksit a, Apichat Imyim a, Removal of ibuprofen, diclofenac, and naproxen fromwater using chitosan-modified waste tire crumb rubber.pdf, (n.d.)

3. Kıdak R, Doğan \$̧ (2018) Effect of coatings and surface modification on porous silicon nanoparticles for delivery of the anticancer drug tamoxifen.pdf. Ultrason Sonochem 40:131-139. https://doi.org/10.1016/j.ultsonch.2017.01.033

4. Nikolaou A, Meric S, Fatta D (2007) Occurrence patterns of pharmaceuticals in water and wastewater environments. Anal Bioanal Chem 387:1225-1234. https://doi.org/10.1007/s00216-006-1035-8

5. Mohammadi Nodeh MK, Radfard M, Zardari LA, Rashidi H, Nodeh (2018) Enhanced removal of naproxen from wastewater using silica magnetic nanoparticles decorated onto graphene oxide; parametric and equilibrium study. Sep Sci Technol 53:2476-2485.

https://doi.org/10.1080/01496395.2018.1457054

6. Illbay Z, Şahin S, Kerkez S, Bayazit (2015) Isolation of naproxen from wastewater using carbon-based magnetic adsorbents. Int J Environ Sci Technol 12:3541-3550. https://doi.org/10.1007/s13762-0150775-4

7. Sellaoui L, Lima EC, Dotto GL, Ben Lamine A (2017) Adsorption of amoxicillin and paracetamol on modified activated carbons: Equilibrium and positional entropy studies. J Mol Liq 234:375-381. https://doi.org/10.1016/j.molliq.2017.03.111

8. Imanipoor J, Mohammadi M, Dinari M, Ehsani MR (2020) Adsorption and Desorption of Amoxicillin Antibiotic from Water Matrices Using an Effective and Recyclable MIL-53(Al) Metal-Organic Framework Adsorbent. J Chem Eng Data. https://doi.org/10.1021/acs.jced.0c00736

9. Brinzila Cl, Monteiro N, Pacheco MJ, Ciríaco L, Siminiceanu I, Lopes A (2014) Degradation of tetracycline at a boron-doped diamond anode: Influence of initial $\mathrm{pH}$, applied current intensity and electrolyte. Environ Sci Pollut Res 21:8457-8465. https://doi.org/10.1007/s11356-014-2778-y

10. Mohammed AA, Kareem SL (2019) Adsorption of tetracycline fom wastewater by using Pistachio shell coated with $\mathrm{ZnO}$ nanoparticles: Equilibrium, kinetic and isotherm studies. Alexandria Eng J 58:917-928. https://doi.org/10.1016/j.aej.2019.08.006

11. Dehghan A, Dehghani MH, Nabizadeh R, Ramezanian N, Alimohammadi M, Najafpoor AA (2018) Adsorption and visible-light photocatalytic degradation of tetracycline hydrochloride from aqueous solutions using 3D hierarchical mesoporous BiOl: Synthesis and characterization, process optimization, adsorption and degradation modeling. Chem Eng Res Des 129:217-230. https://doi.org/10.1016/j.cherd.2017.11.003

12. Gao Y, Li Y, Zhang L, Huang H, Hu J, Shah SM, Su X (2012) Adsorption and removal of tetracycline antibiotics from aqueous solution by graphene oxide. J Colloid Interface Sci 368:540-546. https://doi.org/10.1016/j.jcis.2011.11.015

13. Mahmoodi NM, Abdi J (2019) Nanoporous metal-organic framework (MOF-199): Synthesis, characterization and photocatalytic degradation of Basic Blue 41. Microchem J 144:436-442. https://doi.org/10.1016/j.microc.2018.09.033 
14. Mahmoodi NM, Najafi F (2012) Synthesis, amine functionalization and dye removal ability of titania/silica nano-hybrid. Microporous Mesoporous Mater 156:153-160. https://doi.org/10.1016/j.micromeso.2012.02.026

15. Arami M, Limaee NY, Mahmoodi NM, Tabrizi NS (2005) Removal of dyes from colored textile wastewater by orange peel adsorbent: Equilibrium and kinetic studies. J Colloid Interface Sci 288:371-376. https://doi.org/10.1016/j.jcis.2005.03.020

16. Mahmoodi NM (2014) Dendrimer functionalized nanoarchitecture: Synthesis and binary system dye removal. J Taiwan Inst Chem Eng 45:2008-2020. https://doi.org/10.1016/j.jtice.2013.12.010

17. Mahmoodi NM (2015) Manganese ferrite nanoparticle: Synthesis, characterization, and photocatalytic dye degradation ability, Desalin. Water Treat 53:84-90. https://doi.org/10.1080/19443994.2013.834519

18. Bagheri A, Hoseinzadeh $H$, Hayati B, Mahmoodi NM, Mehraeen E, Post-synthetic functionalization of the metal-organic framework: Clean synthesis, pollutant removal, and antibacterial activity, Biochem. Pharmacol. 3437 (n.d.) 104590. https://doi.org/10.1016/j.jece.2020.104590

19. Shahabadi N, Hadidi S, Shiri F (2020) New water-soluble Fe304@SiO2 magnetic nanoparticles functionalized with levetiracetam drug for adsorption of essential biomolecules by case studies of DNA and HSA. J Biomol Struct Dyn 38:283-294. https://doi.org/10.1080/07391102.2019.1569557

20. Ragab MAA, Korany MA, Ibrahim HZ, Abdel-Kawi MA, E.A.A.A. A, Sayed (2017) Adsorption behavior of some metal ions on nanoparticles used in pharmaceutical matrices: Application to laboratory made drug formulation. Bull Fac Pharmacy Cairo Univ 55:155-162. https://doi.org/10.1016/j.bfopcu.2017.01.002

21. Zuo-Bing X, Xu J, Yun-Wei N, Guang-Yong Z, Xing-Ran K, Effects of surface functional groups on the adhesion of SiO2 nanospheres to bio-based materials, Nanomaterials 9 (2019). https://doi.org/10.3390/nano9101411

22. Koroleva M, Gorbachevski O, Yurtov E (2017) Preparation and characterization of lipid microcapsules coated with SiO2@Al2O3 core-shell nanoparticles as carries for lipophilic drug delivery. Mater Chem Phys 202:1-6. https://doi.org/10.1016/j.matchemphys.2017.08.065

23. Souza MA, de Oliveira KV, Oliveira FCC, Silva LP, Rubim JC (2018) The adsorption of methamphetamine on Ag nanoparticles dispersed in agarose gel - Detection of methamphetamine in fingerprints by SERS. Vib Spectrosc 98:152-157. https://doi.org/10.1016/j.vibspec.2018.08.008

24. Rani GU, Konreddy AK, Mishra S (2018) Novel hybrid biosorbents of agar: Swelling behaviour, heavy metal ions and dye removal efficacies. Int J Biol Macromol 117:902-910. https://doi.org/10.1016/j.jibiomac.2018.05.163

25. Chen L, Li Y, Du Q, Wang Z, Xia Y, Yedinak E, Lou J, Ci L (2017) High performance agar/graphene oxide composite aerogel for methylene blue removal. Carbohydr Polym 155:345-353. https://doi.org/10.1016/j.carbpol.2016.08.047

26. Gu L, He X, Wu Z (2014) Mesoporous hydroxyapatite: Preparation, drug adsorption, and release properties. Mater Chem Phys 148:153-158. https://doi.org/10.1016/j.matchemphys.2014.07.024 
27. Zhang Y, Yan W, Sun Z, Pan C, Mi X, Zhao G, Gao J (2015) Fabrication of porous zeolite/chitosan monoliths and their applications for drug release and metal ions adsorption. Carbohydr Polym 117:657-665. https://doi.org/10.1016/j.carbpol.2014.09.018

28. Li X, Zhang Z, Fakhri A, Gupta VK, Agarwal S (2019) Adsorption and photocatalysis assisted optimization for drug removal by chitosan-glyoxal/Polyvinylpyrrolidone/MoS2 nanocomposites. Int J Biol Macromol 136:469-475. https://doi.org/10.1016/j.ijbiomac.2019.06.003

29. Shagholani H, Ghoreishi SM, Mousazadeh M (2015) Improvement of interaction between PVA and chitosan via magnetite nanoparticles for drug delivery application. Int J Biol Macromol 78:130-136. https://doi.org/10.1016/j.ijbiomac.2015.02.042

30. Hasanzade Z, Raissi H (2019) Assessment of the chitosan-functionalized graphene oxide as a carrier for loading thioguanine, an antitumor drug and effect of urea on adsorption process: Combination of DFT computational and molecular dynamics simulation studies. J Biomol Struct Dyn 37:24872497. https://doi.org/10.1080/07391102.2018.1496140

31. Berthold A, Cremer K, Kreuter J (1996) Preparation and characterization of chitosan microspheres as drug carrier for prednisolone sodium phosphate as model for anti-inflammatory drugs. J Control Release 39:17-25. https://doi.org/10.1016/0168-3659(95)00129-8

32. Sarti E, Chenet T, Stevanin C, Costa V, Cavazzini A, Catani M, Martucci A, Precisvalle N, Beltrami G, Pasti L, High-silica zeolites as sorbent media for adsorption and pre-concentration of pharmaceuticals in aqueous solutions, Molecules 25 (2020).

https://doi.org/10.3390/molecules25153331

33. Chang EE, Wan JC, Kim H, Liang CH, Dai YD, Chiang PC, Adsorption of selected pharmaceutical compounds onto activated carbon in dilute aqueous solutions exemplified by acetaminophen, diclofenac, and sulfamethoxazole, Sci. World J (2015 (2015)) https://doi.org/10.1155/2015/186501

34. Zhao S, Zhang S, Ma J, Fan L, Yin C, Lin G, Li Q (2015) Double loaded self-decomposable SiO2 nanoparticles for sustained drug release. Nanoscale 7:16389-16398. https://doi.org/10.1039/c5nr03029c

35. Kyzas GZ, Bikiaris DN (2015) Recent modifications of chitosan for adsorption applications: A critical and systematic review. Mar Drugs 13:312-337. https://doi.org/10.3390/md13010312

36. Kyzas GZ, Bikiaris DN (2015) Recent Modifications of Chitosan for Adsorption Applications:. Mar Drugs 13:312-337

37. Catauro M, Barrino F, Dal Poggetto G, Milazzo M, Blanco I, Vecchio Ciprioti S (2020) Structure, drug absorption, bioactive and antibacterial properties of sol-gel SiO2/ZrO2 materials. Ceram Int 46:29459-29465. https://doi.org/10.1016/j.ceramint.2020.03.167

38. Varshosaz J, Zaki MR, Minaiyan M, Banoozadeh J, Preparation, optimization, and screening of the effect of processing variables on agar nanospheres loaded with bupropion $\mathrm{HCl}$ by a D-optimal design, Biomed Res. Int (2015 (2015)) https://doi.org/10.1155/2015/571816

39. Tzereme A, Christodoulou E, Kyzas GZ, Kostoglou M, Bikiaris DN, Lambropoulou DA, Chitosan grafted adsorbents for diclofenac pharmaceutical compound removal from single-component 
aqueous solutions and mixtures, Polymers (Basel). 11 (2019).

https://doi.org/10.3390/polym11030497

40. Sani AH-B, Rahmani A, Removal of sulfadimethoxine antibiotic from aqueous solutions using carbon nanotubes.pdf, (n.d.)

41. Rakhshaei R, Namazi H, Hamishehkar H, Kafil HS, Salehi R, In situ synthesized chitosan-gelatin/ZnO nanocomposite scaffold with drug delivery properties: Higher antibacterial and lower cytotoxicity effects, J Appl Polym Sci 136 (2019). https://doi.org/10.1002/app.47590

42. Ning J, Zhang J, Pan Y, Guo J (2003) Fabrication and mechanical properties of SiO2 matrix composites reinforced by carbon nanotube. Mater Sci Eng A 357:392-396. https://doi.org/10.1016/S0921-5093(03)00256-9

43. Sepehr MN, Al-Musawi TJ, Ghahramani E, Kazemian H, Zarrabi M (2017) Adsorption performance of magnesium/aluminum layered double hydroxide nanoparticles for metronidazole from aqueous solution. Arab J Chem 10:611-623. https://doi.org/10.1016/j.arabjc.2016.07.003

44. D.C.I.A. Dra C. Hazel Penichel, Dra C, Niuris Acostall DCCP, Est (2019) Lorenzo GarcíaIV, Tec. Nancy Badal, Dra C. Angeles Herasll, Calcium cross-linked carboxymethylchitosan/alginate microparticles as a system for the prolonged release of ketoprofen. Rev Cuba Química 31:37-57

45. Ramalla I, Gupta RK, Bansal K (2015) Effect on superhydrophobic surfaces on electrical porcelain insulator, improved technique at polluted areas for longer life and reliability. Int J Eng Technol 4:509. https://doi.org/10.14419/ijet.v4i4.5405

46. Samiey B, Ashoori F, Adsorptive removal of methylene blue by agar: Effects of $\mathrm{NaCl}$ and ethanol, Chem Cent J 6 (2012). https://doi.org/10.1186/1752-153X-6-14

47. Of F, Fabrication of chitosan/agarose scaffolds containing extracellular matrix for tissue engineering applications.pdf, (1988) 1-4

48. Badawy MEI, Lotfy TMR, Shawir SMS, Preparation and antibacterial activity of chitosan-silver nanoparticles for application in preservation of minced meat, Bull Natl Res Cent 43 (2019). https://doi.org/10.1186/s42269-019-0124-8

49. Widhi Mahatmanti F (2014) Nuryono, Narsito, Physical characteristics of chitosan based film modified with silica and polyethylene glycol. Indones J Chem 14:131-137. https://doi.org/10.22146/ijc. 21249

50. Mahmoodi NM, Taghizadeh M, Taghizadeh A (2019) Activated carbon/metal-organic framework composite as a bio-based novel green adsorbent: Preparation and mathematical pollutant removal modeling. J Mol Liq 277:310-322. https://doi.org/10.1016/j.molliq.2018.12.050

51. Mahmoodi NM, Taghizadeh A, Taghizadeh M, Azimi M (2019) Surface modified montmorillonite with cationic surfactants: Preparation, characterization, and dye adsorption from aqueous solution. J Environ Chem Eng 7:103243. https://doi.org/10.1016/j.jece.2019.103243

52. Almasian A, Olya ME, Mahmoodi NM (2015) Synthesis of polyacrylonitrile/polyamidoamine composite nanofibers using electrospinning technique and their dye removal capacity. J Taiwan Inst Chem Eng 49:119-128. https://doi.org/10.1016/j.jtice.2014.11.027 
53. Hosseinabadi-Farahani Z, Hosseini-Monfared H, Mahmoodi NM (2015) Graphene oxide nanosheet: preparation and dye removal from binary system colored wastewater, Desalin. Water Treat 56:23822394. https://doi.org/10.1080/19443994.2014.960462

54. Naseri A, Samadi M, Mahmoodi NM, Pourjavadi A, Mehdipour H, Moshfegh AZ, Tuning Composition of Electrospun ZnO/CuO Nanofibers: Toward Controllable and Efficient Solar Photocatalytic Degradation of Organic Pollutants, 2017. https://doi.org/10.1021/acs.jpcc.6b10414

55. El-Maghraby A, El HE, Deeb (2011) Removal of a basic dye from aqueous solution by adsorption using rice hulls, Glob. Nest J 13:90-98. https://doi.org/10.30955/gnj.000560

56. Babaei AA, Alavi SN, Akbarifar M, Ahmadi K, Ramazanpour Esfahani A, Kakavandi B (2016) Experimental and modeling study on adsorption of cationic methylene blue dye onto mesoporous biochars prepared from agrowaste, Desalin. Water Treat 57:27199-27212. https://doi.org/10.1080/19443994.2016.1163736

57. A.M. Seyed Hossein Mousavi1*, Synthesis of $\beta$-cyclodextrin-glycine-modified TiO2 nanoparticles for adsorption of dyes from aqueous solutions.pdf, (n.d.)

58. Jawad AH, Rashid RA, Mahmuod RMA, Ishak MAM, Kasim NN, Ismail K (2016) Adsorption of methylene blue onto coconut (Cocos nucifera) leaf: optimization, isotherm and kinetic studies. Desalin Water Treat 57:8839-8853. https://doi.org/10.1080/19443994.2015.1026282

59. Banerjee S, Chattopadhyaya MC (2017) Adsorption characteristics for the removal of a toxic dye, tartrazine from aqueous solutions by a low cost agricultural by-product. Arab J Chem 10:S1629S1638. https://doi.org/10.1016/j.arabjc.2013.06.005

60. Umpuch C, Sakaew S, Removal of methyl orange from aqueous solutions by adsorption using chitosan intercalated montmorillonite, Songklanakarin J. Sci. Technol. 35 (2013)

\section{Figures}
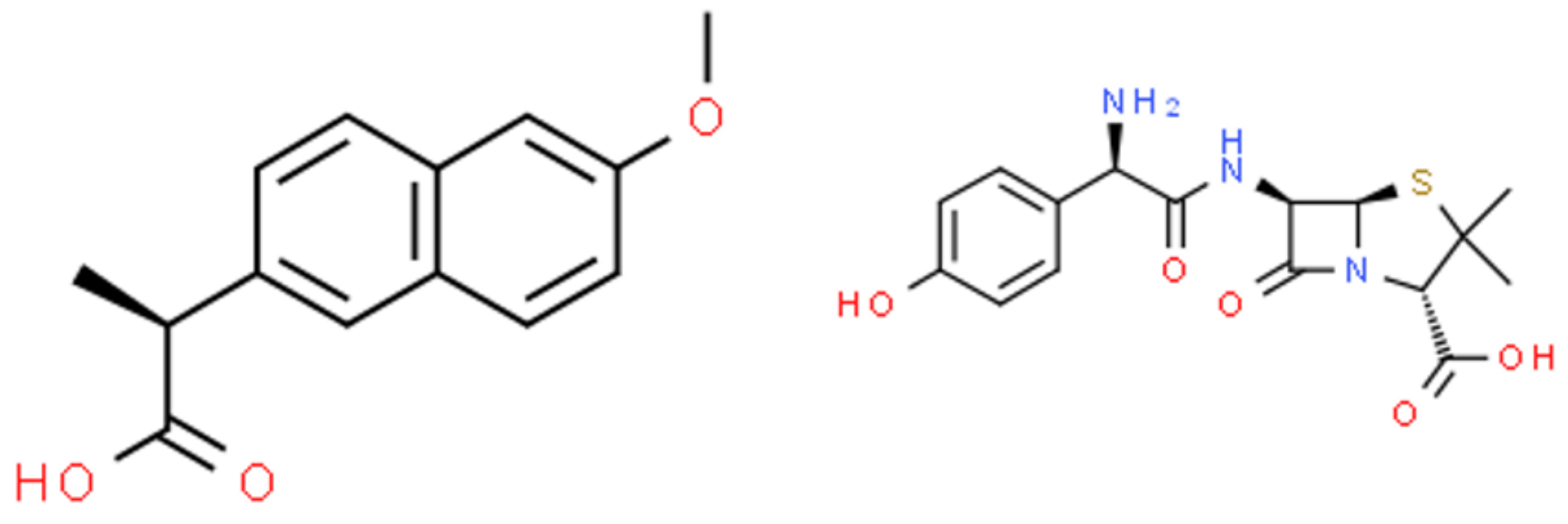

Figure 1 
The chemical structure of naproxen (a) and amoxicillin (b).

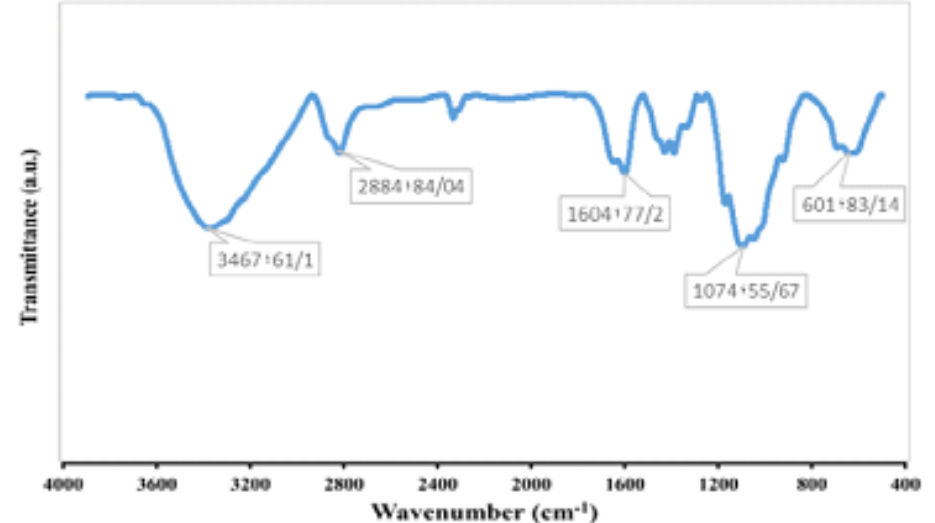

(a)

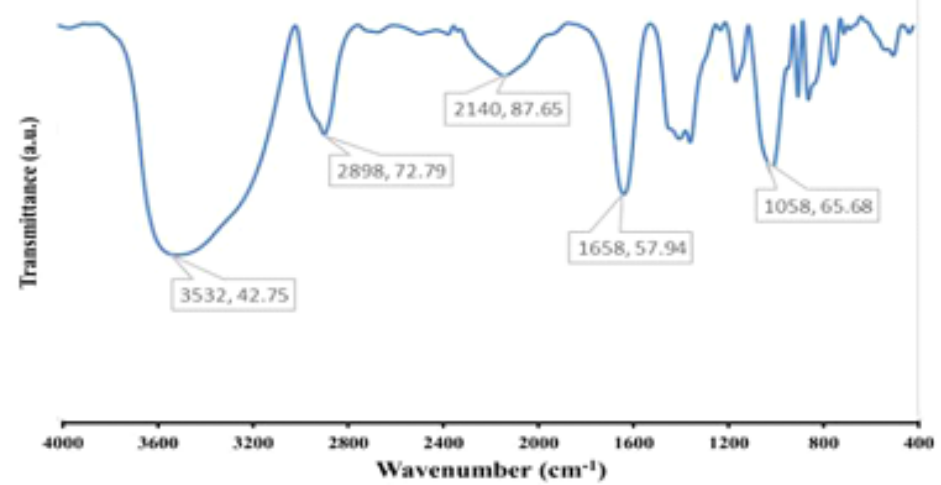

(c)

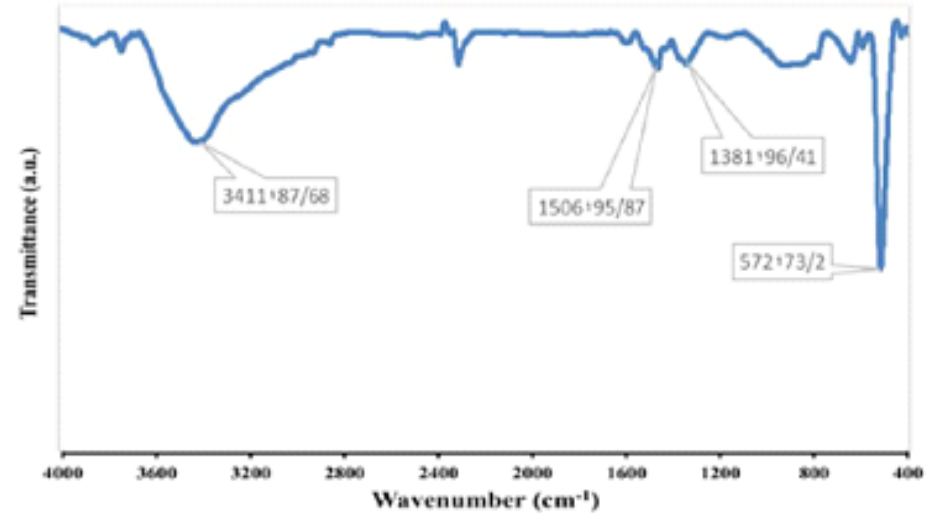

(e)

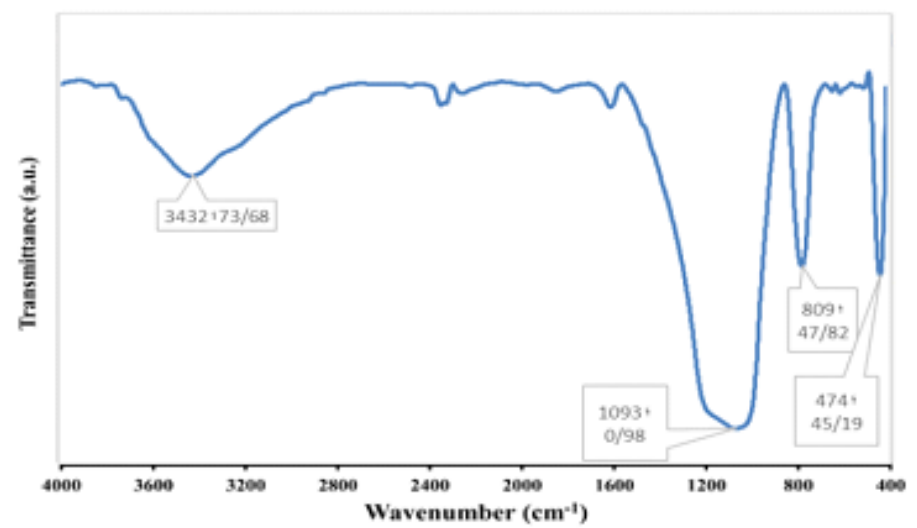

(b)

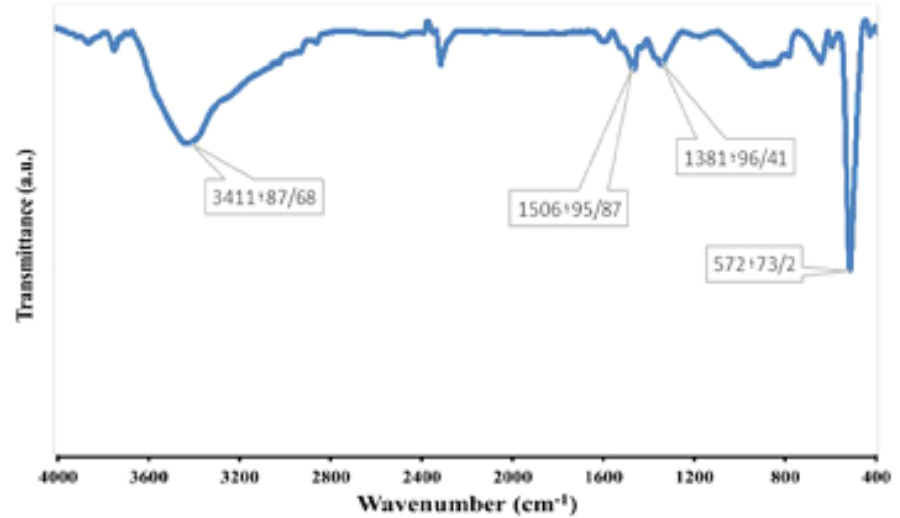

(d)

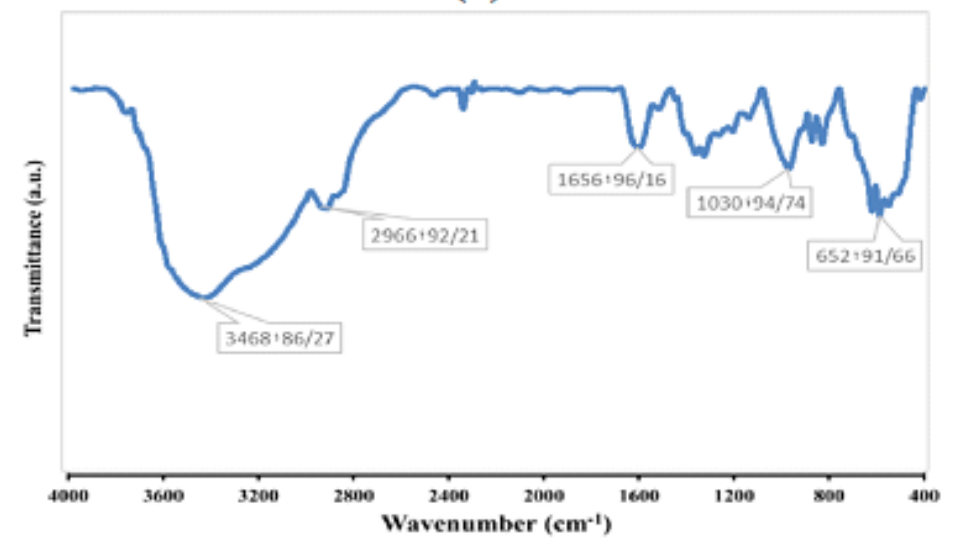

(f)

Figure 2

FTIR spectra of (a) chitosan; (b) SiO2; (c) Agar; (d) Agar/Chitosan; (e) Chitosan/SiO2; (f) Chitosan/Agar/SiO2. 


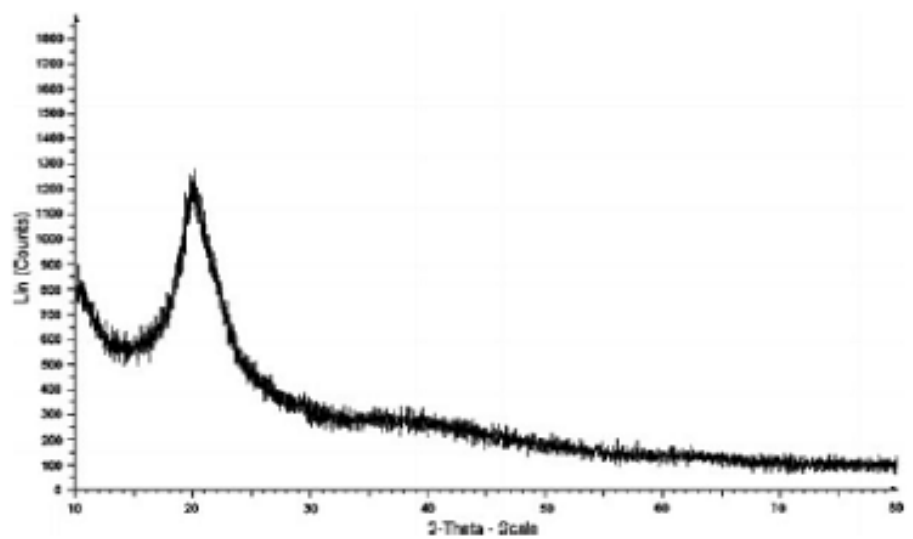

(a)

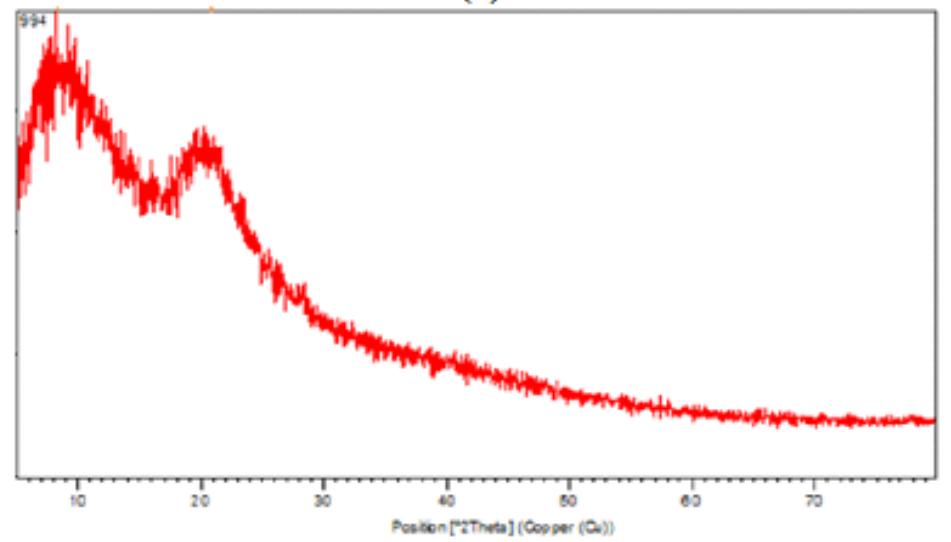

(c)

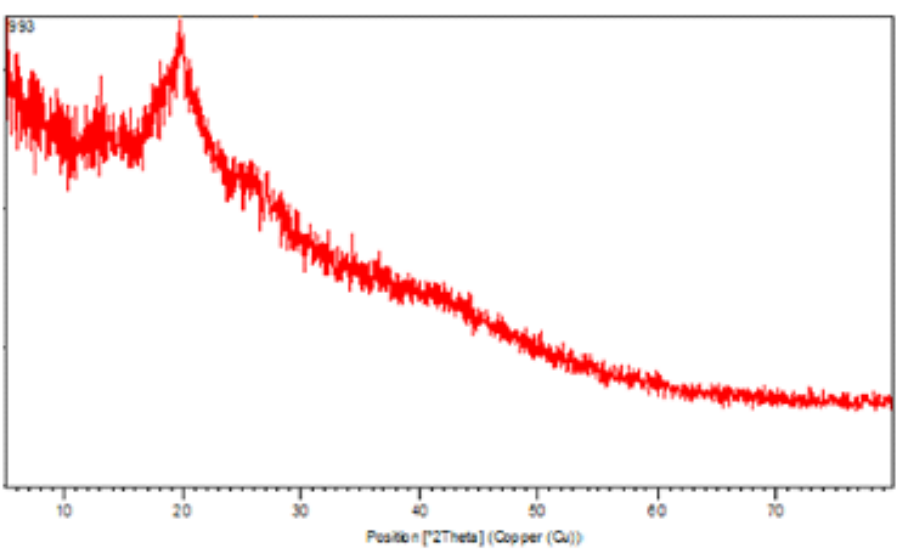

(e)

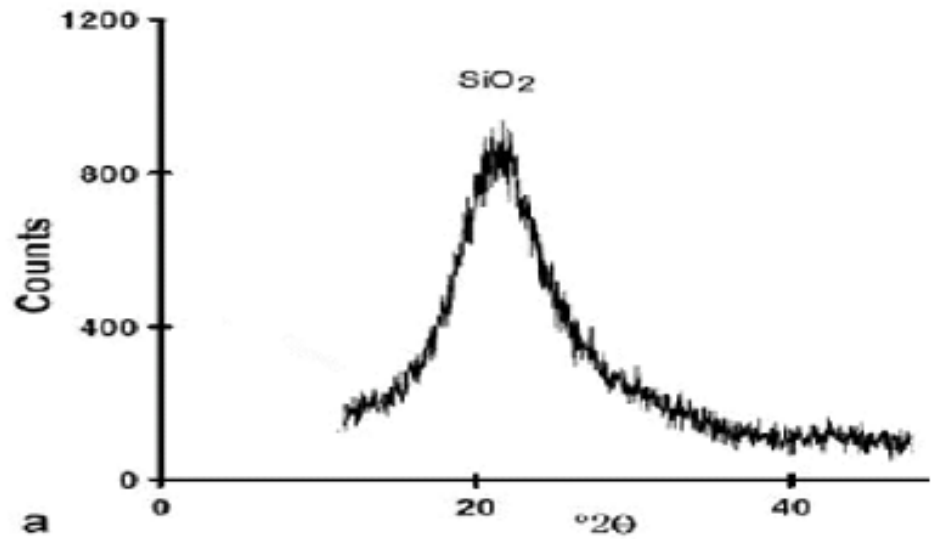

(b)

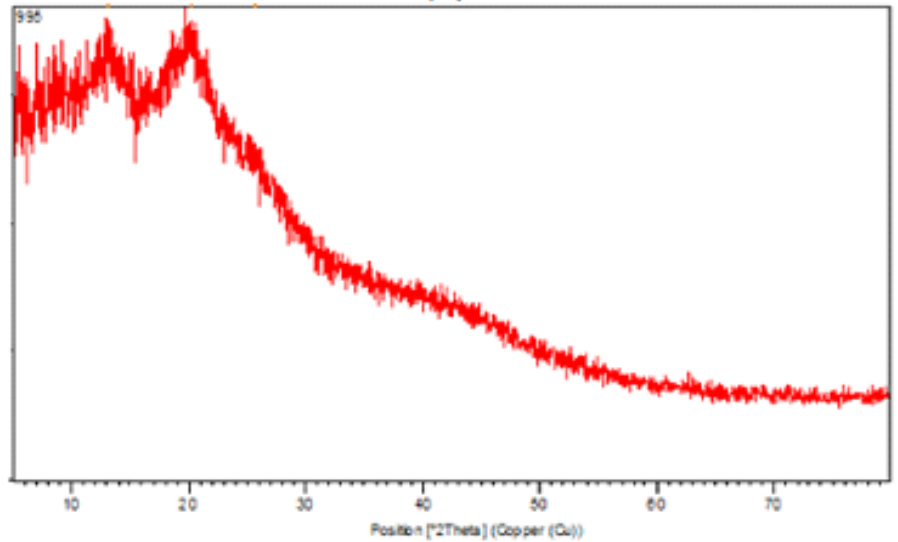

(d)

Figure 3

XRD pattern of (a) chitosan; (b) SiO2; (c) chitosan/SiO2; (d) Agar/Chitosan; (e) Chitosan/Agar/SiO2. 

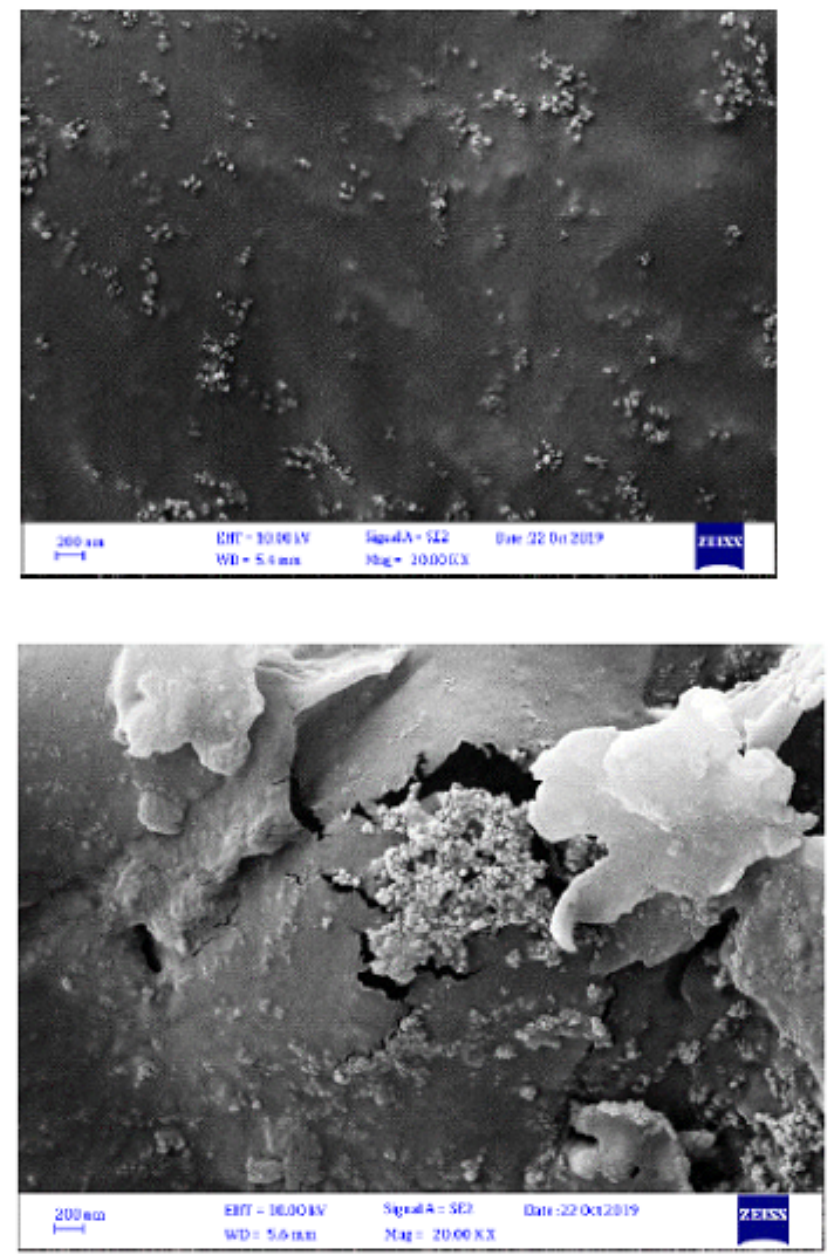

(a)

(b)
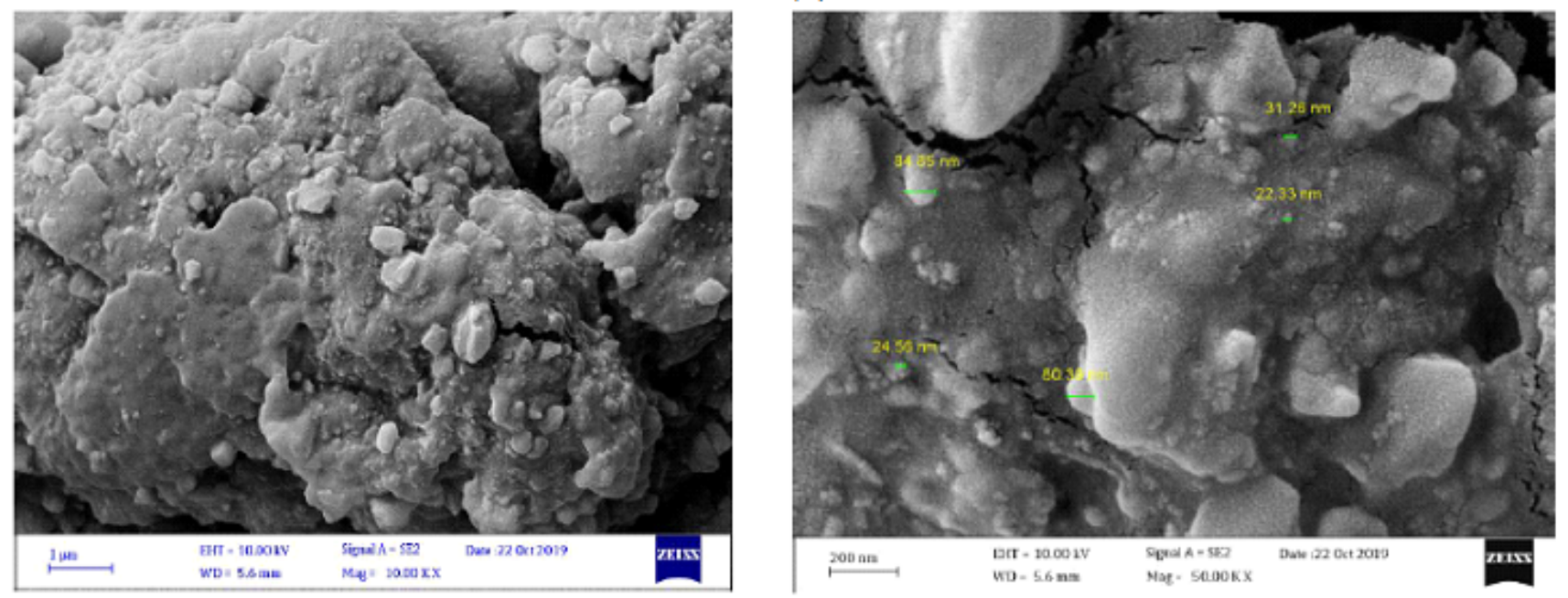

(c)
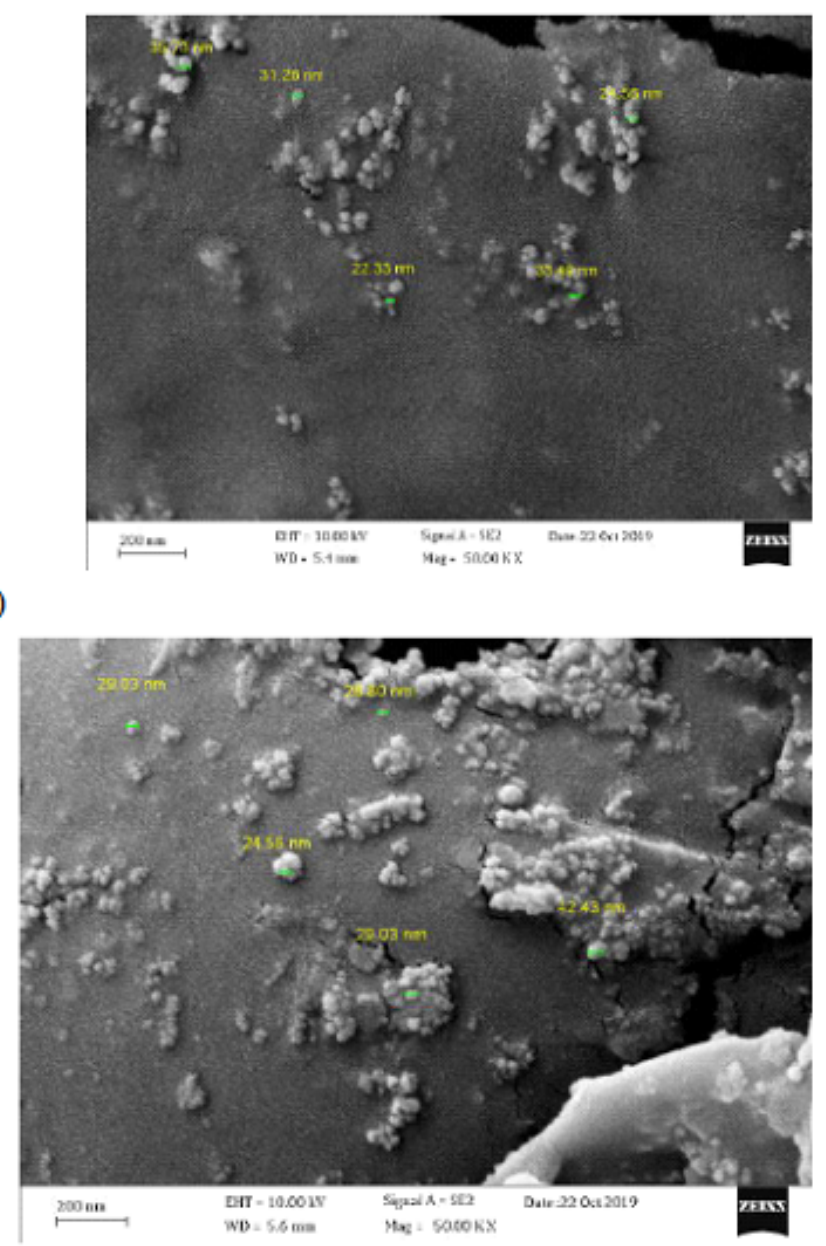

(b)

\section{Figure 4}

SEM images: (a) Agar/Chitosan; (b) Chitosan/SiO2; (c) Chitosan/Agar/SiO2. 


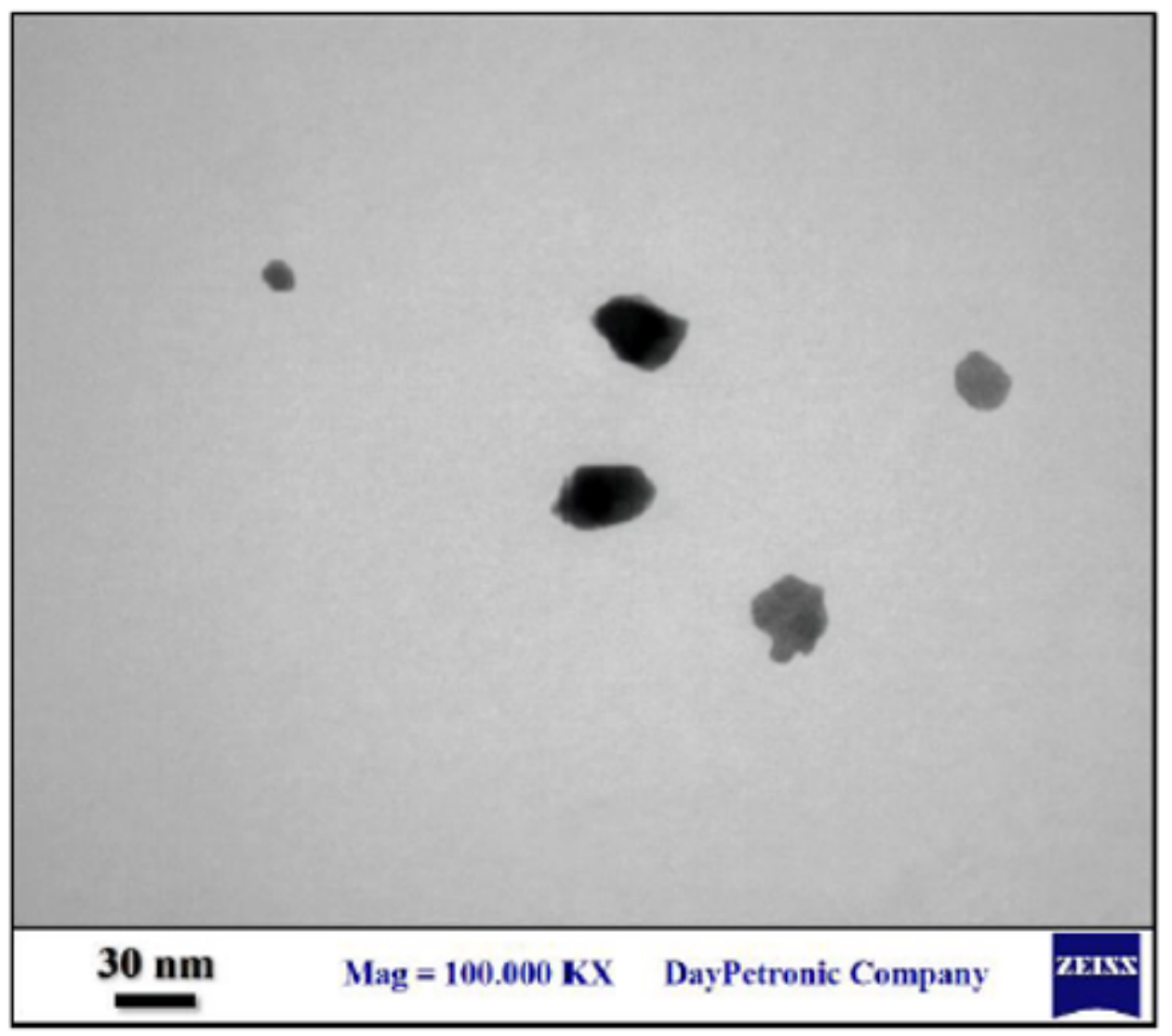

Figure 5

TEM images Chitosan/Agar/SiO2. 

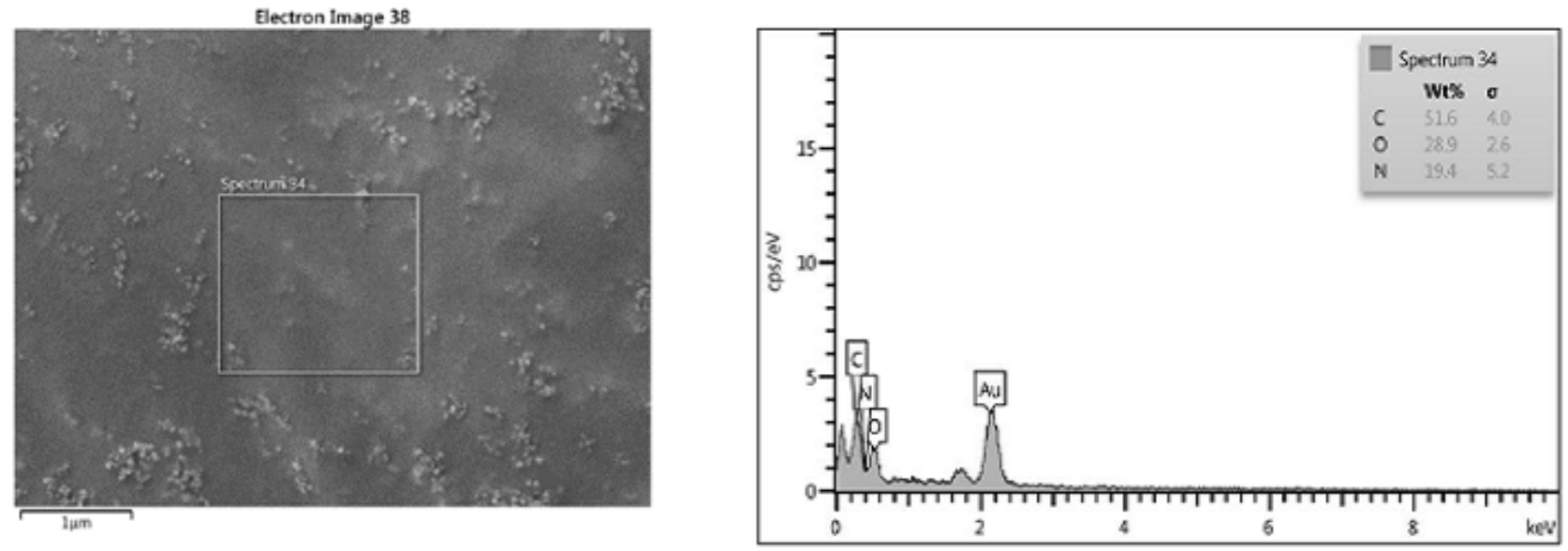

(a)
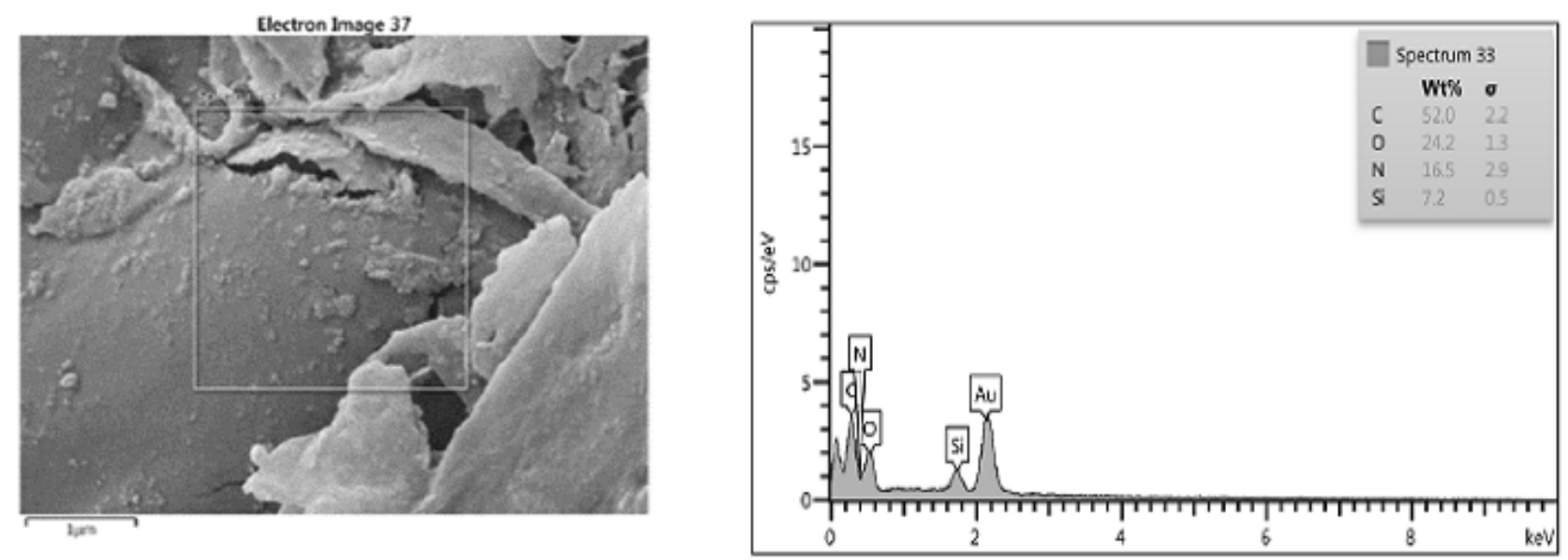

(b)
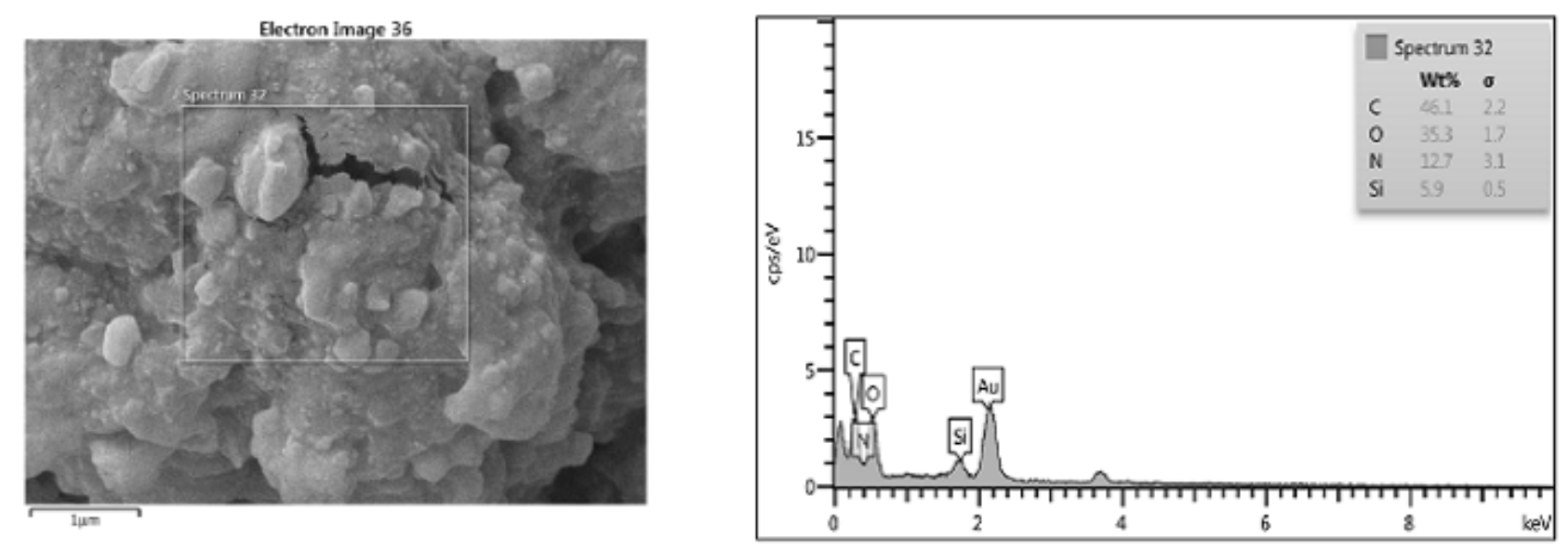

(c)

\section{Figure 6}

EDX images: (a) Agar/Chitosan; (b) Chitosan/SiO2; (c) Chitosan/Agar/SiO2. 


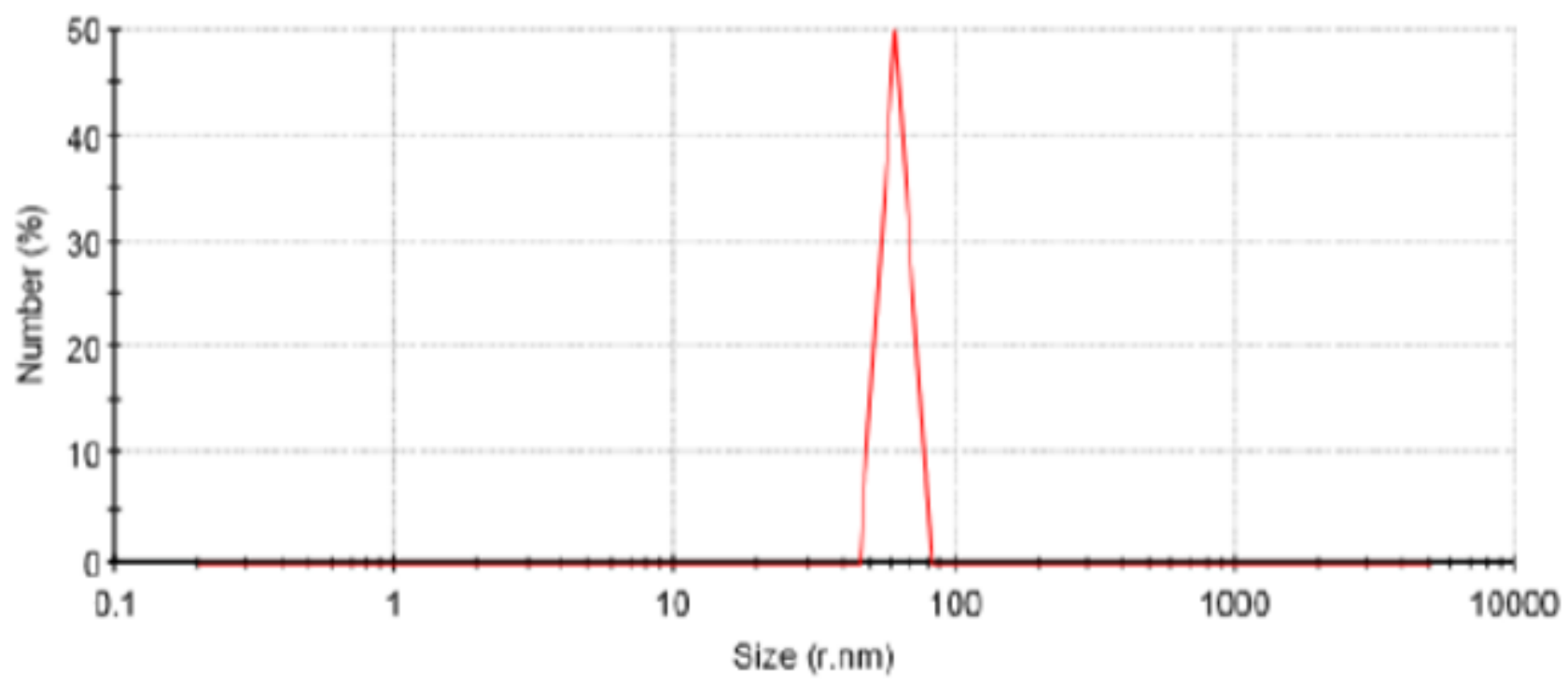

Figure 7

DLS images Agar/GO/ZnO.

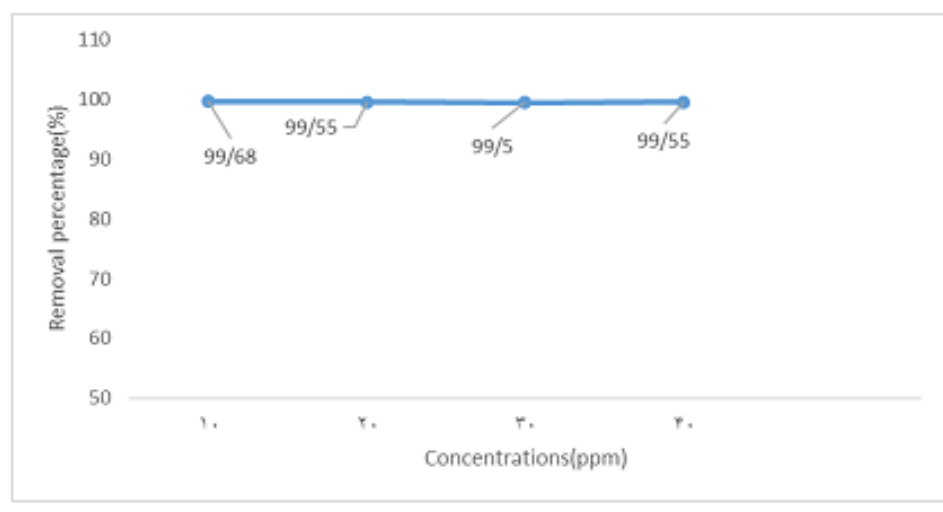

(a)

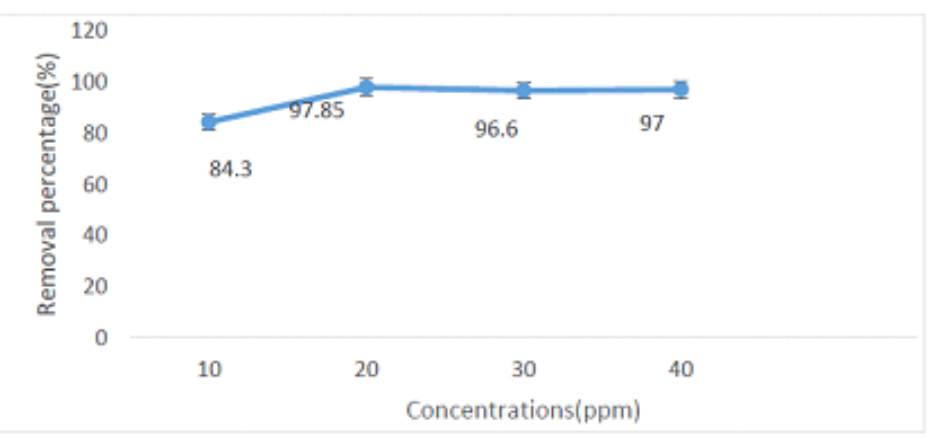

(c)

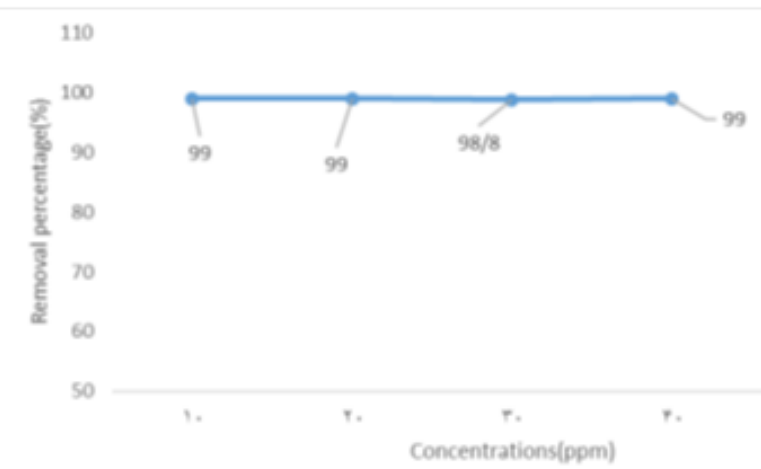

(b)

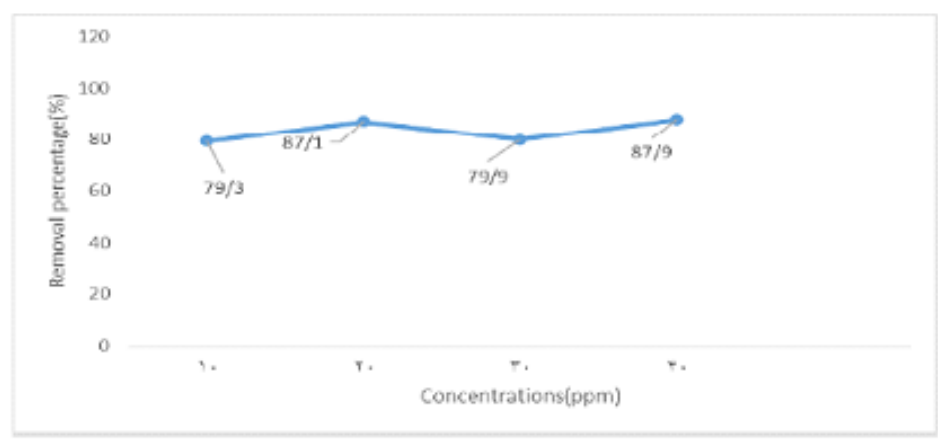

(d)

\section{Figure 8}

Effect of initial concentration pollutants (10,20,30, and $40 \mathrm{mg} / \mathrm{l})$ (a) Agar/chitosan on naproxen; (b) Agar/chitosan/SiO2 for on naproxen; (c) Agar/chitosan on amoxicillin; (d) Agar/chitosan/SiO2 for on amoxicillin. 


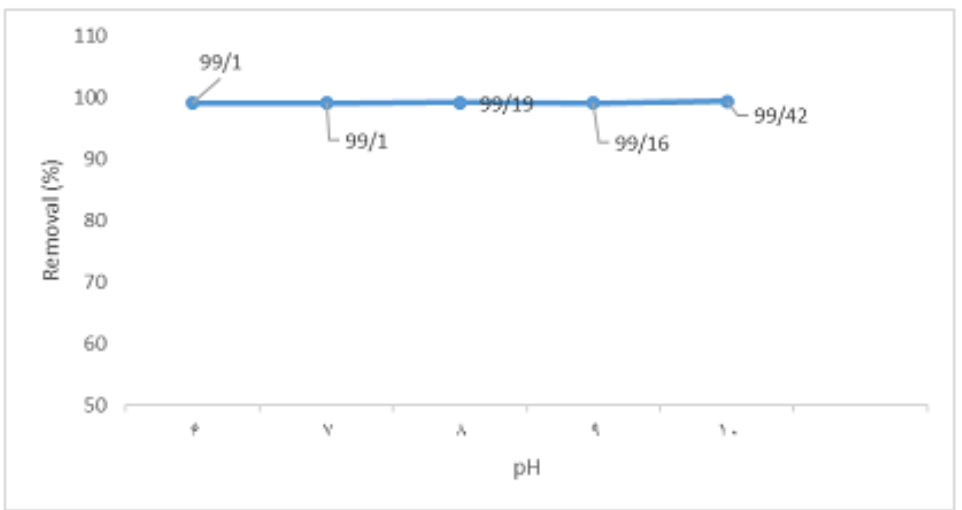

(a)

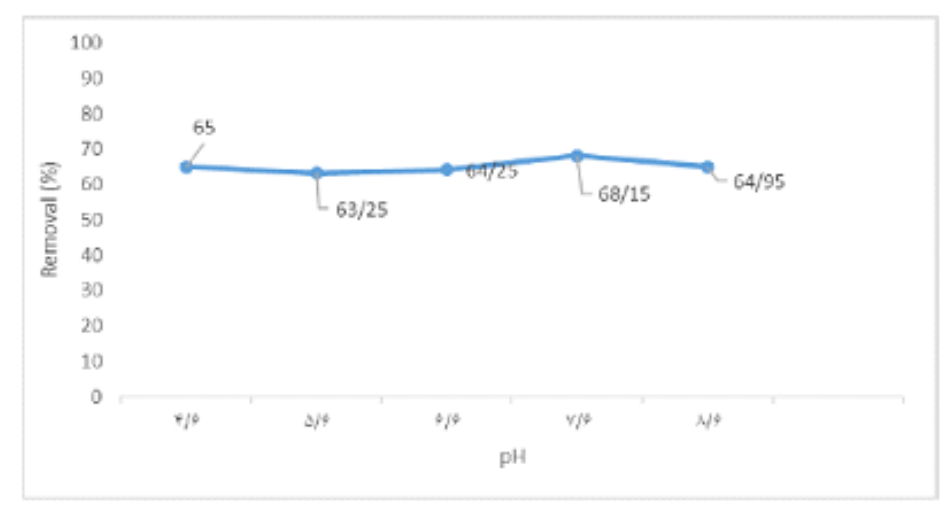

(c)

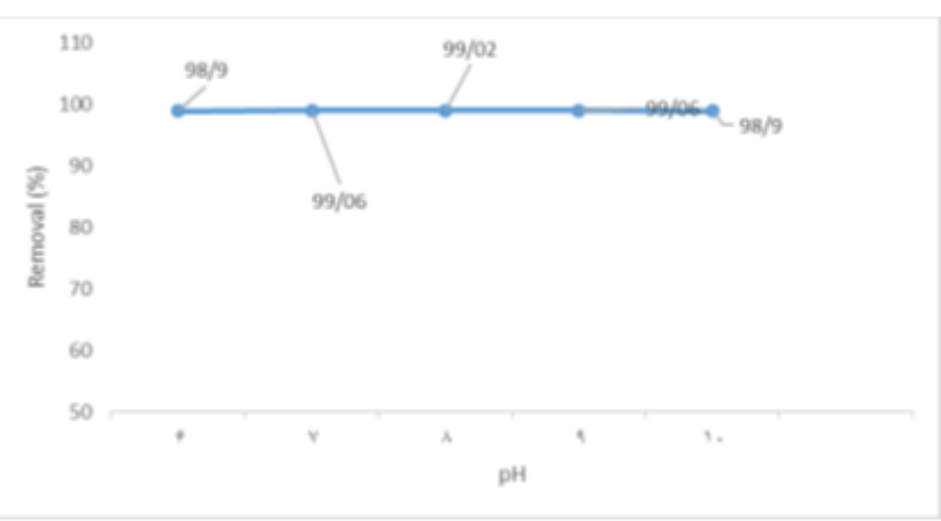

(b)

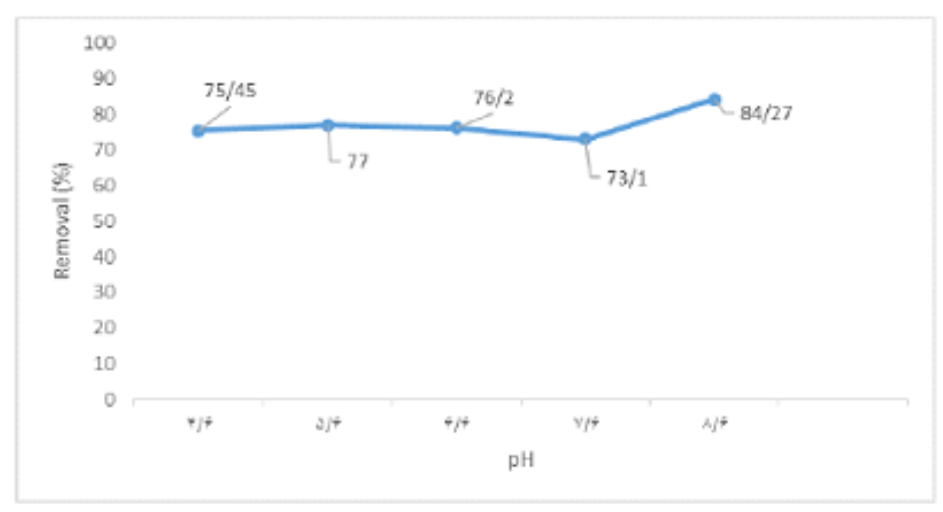

(d)

\section{Figure 9}

Effect of $\mathrm{pH}(4.5,5.5,6.5,7.5$, and 8.5) (a) Agar/chitosan on naproxen; (b) Agar/chitosan/SiO2 for on naproxen; (c) Agar/chitosan on amoxicillin; (d) Agar/chitosan/SiO2 for on amoxicillin. 


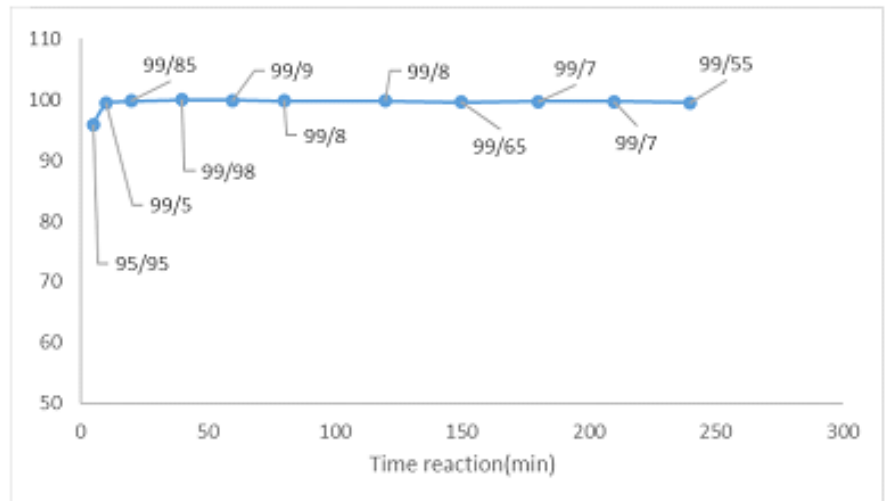

(a)

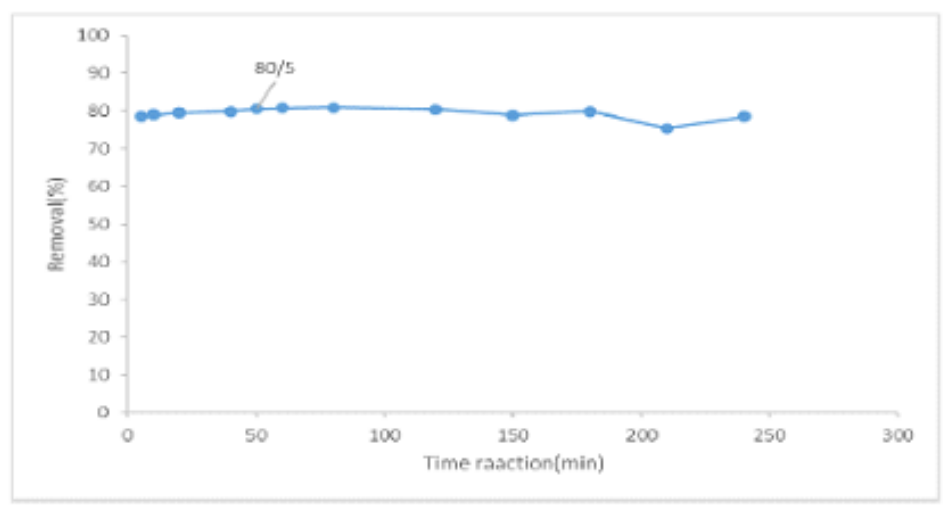

(c)

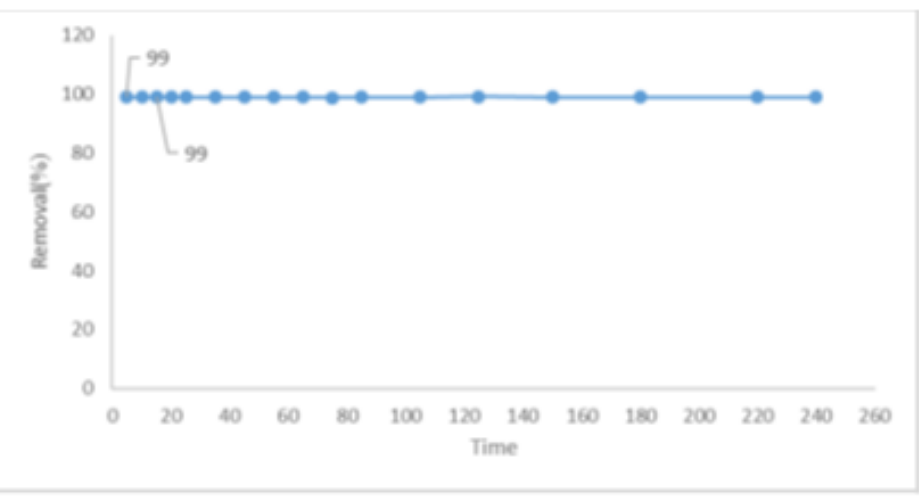

(b)

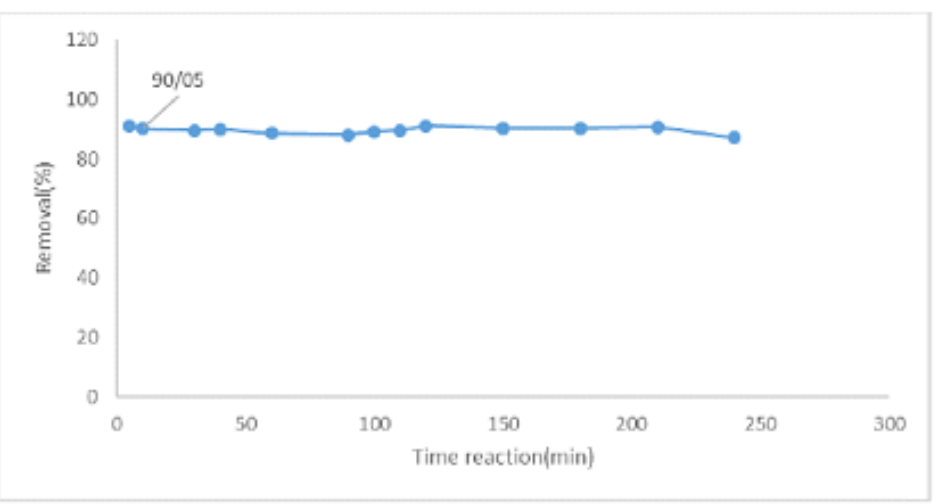

(d)

\section{Figure 10}

Effect of contact time (a) Agar/chitosan on naproxen; (b) Agar/chitosan/SiO2 for on naproxen; (c) Agar/chitosan on amoxicillin; (d) Agar/chitosan/SiO2 for on amoxicillin. 


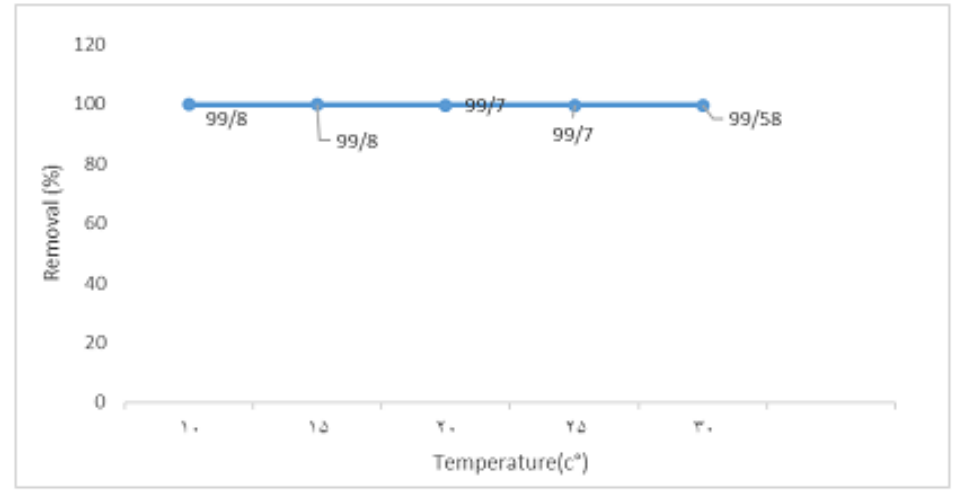

(a)

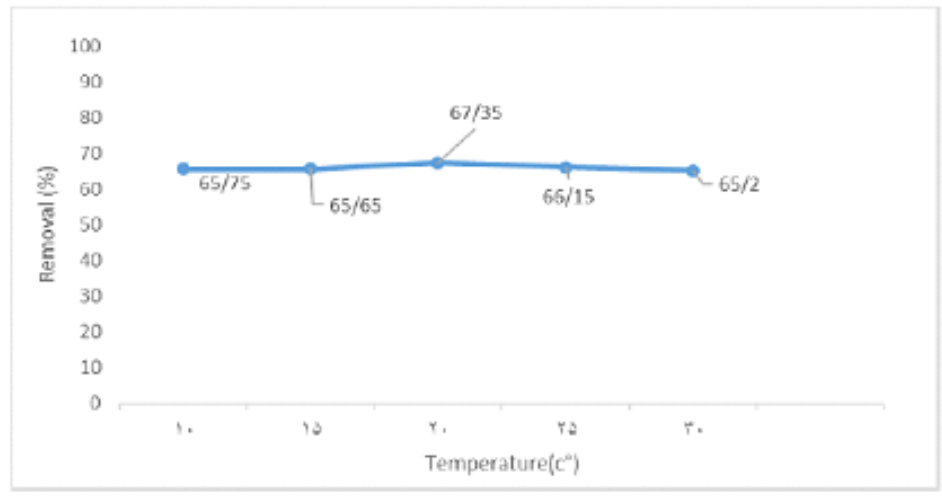

(c)

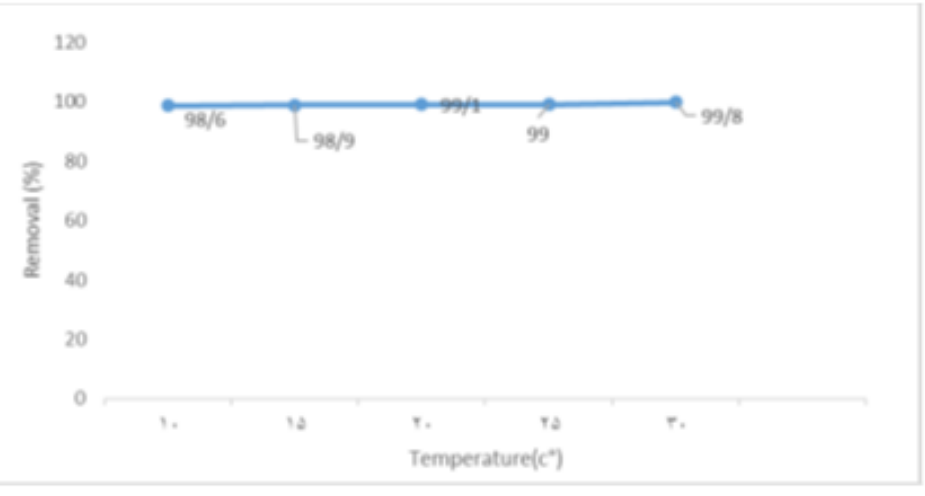

(b)

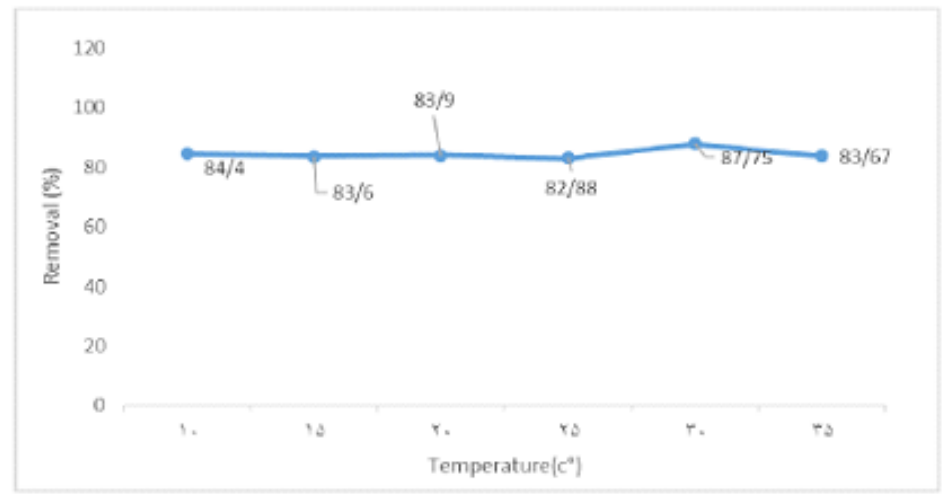

(d)

\section{Figure 11}

Impact of temperature (10, 15, 20, 25, and 30) (a) Agar/chitosan on naproxen; (b) Agar/chitosan/SiO2 for on naproxen; (c) Agar/chitosan on amoxicillin; (d) Agar/chitosan/SiO2 for on amoxicillin. 